\title{
Evaluating climate model performance with various parameter sets using observations over the recent past
}

\author{
M. F. Loutre ${ }^{1}$, A. Mouchet ${ }^{2}$, T. Fichefet ${ }^{1}$, H. Goosse ${ }^{1}$, H. Goelzer ${ }^{3}$, and P. Huybrechts ${ }^{3}$ \\ ${ }^{1}$ Université catholique de Louvain, Earth and Life Institute, Georges Lemaître Centre for Earth and Climate Research \\ (TECLIM), Chemin du Cyclotron, 2 bte L7.01.11, 1348 Louvain-la-Neuve, Belgium \\ ${ }^{2}$ Laboratoire de Physique Atmosphérique et Planétaire, Université de Liège, Allée du 6 août, 17, Bâtiment B5c, \\ 4000 Liège, Belgium \\ ${ }^{3}$ Earth System Science \& Departement Geografie, Vrije Universiteit Brussel, Pleinlaan, 2, 1050 Brussels, Belgium
}

Received: 6 April 2010 - Published in Clim. Past Discuss.: 29 April 2010

Revised: 19 April 2011 - Accepted: 20 April 2011 - Published: 17 May 2011

\begin{abstract}
Many sources of uncertainty limit the accuracy of climate projections. Among them, we focus here on the parameter uncertainty, i.e. the imperfect knowledge of the values of many physical parameters in a climate model. Therefore, we use LOVECLIM, a global three-dimensional Earth system model of intermediate complexity and vary several parameters within a range based on the expert judgement of model developers. Nine climatic parameter sets and three carbon cycle parameter sets are selected because they yield present-day climate simulations coherent with observations and they cover a wide range of climate responses to doubled atmospheric $\mathrm{CO}_{2}$ concentration and freshwater flux perturbation in the North Atlantic. Moreover, they also lead to a large range of atmospheric $\mathrm{CO}_{2}$ concentrations in response to prescribed emissions. Consequently, we have at our disposal 27 alternative versions of LOVECLIM (each corresponding to one parameter set) that provide very different responses to some climate forcings. The 27 model versions are then used to illustrate the range of responses provided over the recent past, to compare the time evolution of climate variables over the time interval for which they are available (the last few decades up to more than one century) and to identify the outliers and the "best" versions over that particular time span. For example, between 1979 and 2005, the simulated global annual mean surface temperature increase ranges from $0.24^{\circ} \mathrm{C}$ to $0.64{ }^{\circ} \mathrm{C}$, while the simulated increase in atmospheric $\mathrm{CO}_{2}$ concentration varies between 40 and 50 ppmv. Measurements over the same period indicate an increase in
\end{abstract}

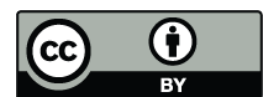

Correspondence to: M. F. Loutre (marie-france.loutre@uclouvain.be) global annual mean surface temperature of $0.45^{\circ} \mathrm{C}$ (Brohan et al., 2006) and an increase in atmospheric $\mathrm{CO}_{2}$ concentration of 44 ppmv (Enting et al., 1994; GLOBALVIEW-CO2, 2006). Only a few parameter sets yield simulations that reproduce the observed key variables of the climate system over the last decades. Furthermore, our results show that the model response, including its ocean component, is strongly influenced by the model sensitivity to an increase in atmospheric $\mathrm{CO}_{2}$ concentration but much less by its sensitivity to freshwater flux in the North Atlantic. They also highlight weaknesses of the model, in particular its large ocean heat uptake.

\section{Introduction}

Policymakers are facing a wide range of possible scenarios for long-term climate and sea level evolution without knowing precisely why they differ and how reliable they are (e.g. IPCC, 2007; Knutti et al., 2008; Stainforth et al., 2007). There are indeed many sources of uncertainty in modelling experiments used in climate projections. Among others, there are uncertainties in the future anthropogenic emissions of greenhouse gases and aerosols (e.g. Nakicenovic and Swart, 2000; Meehl et al., 2007), and uncertainties in the boundary and initial conditions (e.g. Knutti et al., 2008). Moreover, climate models, and in particular the physical parameterisations they are using, are far from being perfect and the values of many physical parameters themselves are often poorly known (e.g. Stainforth et al., 2005; Murphy et al., 2004). 
Several strategies can be used to assess those uncertainties. Model results can be analysed to quantify the errors in the simulations. For example, Gleckler et al. (2008) proposed objective measures of coupled ocean-atmosphere general circulation model performance according to several climatic variables. They evaluate the model performance according to 2-D climatic fields simulated for a given climate state. Therefore, they calculate the root mean square (RMS) errors for each model and each variable using two references. They define a "typical" model error, i.e. the median of the RMS error calculations for each climatic variable, which is used to normalize the RMS error for each variable. So, they obtain a measure of how well a given General Circulation Model (GCM) compares with the typical model error. In parallel, the modelled responses to different external forcings are utilised to illustrate the uncertainty related to the non-perfect knowledge of the forcing (e.g. Crowley, 2000; Bertrand et al., 2002). Another example of strategy to assess model uncertainty is given by Murphy et al. (2004) and Stainforth et al. (2005). They used the same model and the same forcings with varied values of key physical parameters to identify the range of the climate response to a $\mathrm{CO}_{2}$ doubling related to parameter uncertainty. Lastly, Knutti et al. (2008) gave another example of strategy. Based on several emission scenarios and coupled GCMs, they concluded that the contribution of structural uncertainties (i.e. the error related to the choices made in the model structure that would remain even if all the parameters were perfectly known) to temperature projection over the next century is quite large (Knutti et al., 2008).

Among all those possible sources of uncertainty, we focus here on the parameter uncertainty in LOVECLIM, a global three-dimensional Earth system model of intermediate complexity (Goosse et al., 2010). The overall goal of this study is to design several alternative model versions that provide a wide range of climate responses to a climate forcing. Therefore, we identify a reasonable number of parameter sets that yield present climate simulations coherent with observations. Moreover, the various parameter sets should lead to a wide range of possible climate responses to increase in atmospheric $\mathrm{CO}_{2}$ concentration and to freshwater discharge in the North Atlantic. They will thus provide a reasonable sample for quantifying the uncertainty of future climate changes in forthcoming studies. This approach has been chosen rather than a systematic random variation of important parameters because the latter would imply a very large number of long simulations, which is not affordable even with a relatively fast model like LOVECLIM. Moreover, preliminary tests clearly showed that most parameter combinations lead to unrealistic present-day climate and therefore would be useless for the purpose of this study. In addition, using a restricted number of parameter sets allows a better knowledge of their characteristics and thus potentially offers a better understanding of the different responses.
After a brief model description (Sect. 2), the remainder of the paper is divided into two major parts. First, we present the design of the alternative model versions (Sect. 3). Twenty-seven combinations of key physical parameter values of LOVECLIM that have a large impact on the model results are selected and utilised to carry out transient experiments over the last millennium. In the second part (Sect. 4), we use these model versions to analyse the range of responses to given forcings over the recent past. In particular, we focus on the ability of the model to simulate the trend of key global climate variables over the last century and, therefore, we design a metric (i.e. a scalar measure) to quantify this ability. The last century was chosen because it corresponds to a period when relatively accurate observations are available for model-data comparison. Furthermore, as LOVECLIM has been (and is still) mainly used in process studies focused on mid- and high latitudes, we select variables that potentially have a direct or indirect impact on the evolution of sea level, on the stability of the North Atlantic meridional overturning circulation (MOC) and on the future of the climate of polar regions. We also select global variables that give a global view on climate change. Therefore, in addition to atmospheric $\mathrm{CO}_{2}$ concentration and surface temperature, we specifically assess the ability of the model to reproduce the observed trends in the Northern Hemisphere sea ice extent and global ocean heat content.

\section{The climate model - description}

LOVECLIM1.1 (further termed LOVECLIM) is a 3-D Earth System Model of Intermediate Complexity (EMIC). It consists of five components representing the atmosphere (ECBilt), the ocean and sea ice (CLIO), the terrestrial biosphere (VECODE), the oceanic carbon cycle (LOCH) and the Greenland and Antarctic ice sheets (AGISM). The ice sheet model AGISM (Huybrechts, 1990, 1996; Huybrechts and de Wolde, 1999) is not activated in this study because of the negligible influence of ice sheet-climate interactions on the climate evolution over the last century. Rather, its influence on future climate simulations is investigated in a separate study (Goelzer et al., 2010). The previous model version (LOVECLIM1.0) is described in Driesschaert et al. (2007), while version 1.2 , which differs only very slightly from version 1.1, is presented in Goosse et al. (2010).

ECBilt (Opsteegh et al., 1998) is a quasi-geostrophic atmospheric model with 3 levels and T21 horizontal resolution that explicitly computes synoptic variability associated with weather patterns. It includes simple parameterisations of the diabatic heating processes and an explicit representation of the hydrological cycle. Cloudiness is prescribed according to present-day climatology. CLIO (Goosse and Fichefet, 1999 ) is a primitive-equation, free-surface OGCM coupled to a thermodynamic-dynamic sea ice model. Its horizontal resolution is $3^{\circ} \times 3^{\circ}$, and there are 20 levels in the ocean. 

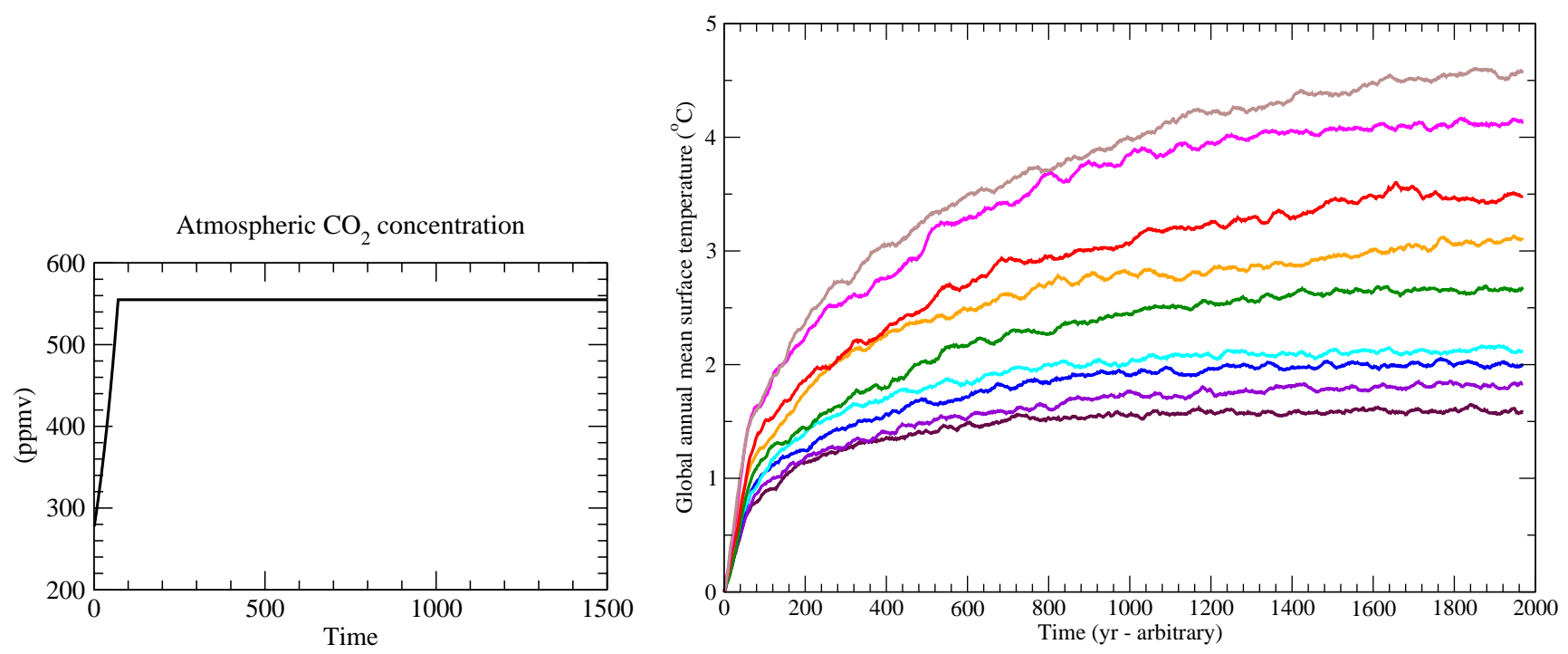

112122212222312322412512522

Fig. 1. Atmospheric $\mathrm{CO}_{2}$ concentration in the perturbation scenario (left) and time evolution of the global annual mean surface temperature in response to this perturbation according to the selected model parameter sets (right). Temperature is presented as deviation from the initial value. The colour code for the parameter sets is given in the figure.

VECODE (Brovkin et al., 2002) is a reduced-form model of the vegetation dynamics and of the terrestrial carbon cycle. It simulates the dynamics of two plant functional types (trees and grassland) at the same resolution as that of ECBILT. LOCH (Mouchet and François, 1996; Mouchet, 2011) is a comprehensive oceanic carbon cycle model that includes an atmospheric module to represent the evolution of $\mathrm{CO}_{2}$, ${ }^{13} \mathrm{CO}_{2}$, and ${ }^{14} \mathrm{CO}_{2}$ in the atmosphere. $\mathrm{LOCH}$ is fully coupled to CLIO and runs with the same time step and on the same grid. LOVECLIM has been utilised in a large number of climate studies (e.g. Driesschaert et al., 2007; Goosse et al., 2007; Menviel et al., 2008a,b) and was part of several model intercomparison exercises (e.g. Braconnot et al., 2002, 2007a,b; Dutay et al., 2004).

\section{Alternative model versions}

\subsection{Introduction - parameter sets}

Several physical parameters of the model may significantly impact the model response to an external perturbation. We performed more than one hundred simulations using combinations of parameters. These simulations were designed to lead to contrasted responses to a doubling of $\mathrm{CO}_{2}$ concentration and to additional freshwater flux in the North Atlantic, and to induce different responses of the carbon cycle model. Amongst them, we selected those that produced reasonable simulations of the present-day climate. Eventually, we kept nine climatic parameter sets and three carbon cycle parameter sets, which makes 27 parameter sets (see Sect. 1 of the Supplement for the description of the parameter sets; a three digit code identifies the parameter set, the first two digits correspond to the climatic parameter sets, and the third one to the carbon cycle parameter set).

\subsection{Sensitivity}

\subsubsection{Sensitivity to $\mathrm{CO}_{2}$ concentration}

A first sensitivity experiment (prefix E, suffix 2CO, Table 1) is performed starting from the equilibrium state simulated under pre-industrial conditions (Sect. 2 of the Supplement). The atmospheric $\mathrm{CO}_{2}$ concentration is increased by $1 \%$ per year from the pre-industrial value until doubling, i.e. after 70 years. It is thereafter held constant (Fig. 1, left). This experiment provides a clear and strong climate signal as well as a good insight into the response of the atmosphere under perturbed conditions. Figure 1 (right) displays the temperature evolution during the first 2000 year time interval of the experiment. The rate of change is largest over the first 70 years of the simulation, when atmospheric $\mathrm{CO}_{2}$ concentration is increasing. The increase in global annual mean surface temperature after 1000 years in this sensitivity experiment is translated into an index to characterise the model in terms of response to the prescribed perturbation (climate sensitivity). Its value ranges from 1 to 5 , corresponding to a temperature increase from less than $2.0^{\circ} \mathrm{C}$ to more than $3.5^{\circ} \mathrm{C}$ (by step of $0.5^{\circ} \mathrm{C}$ ) in the experiment described above 


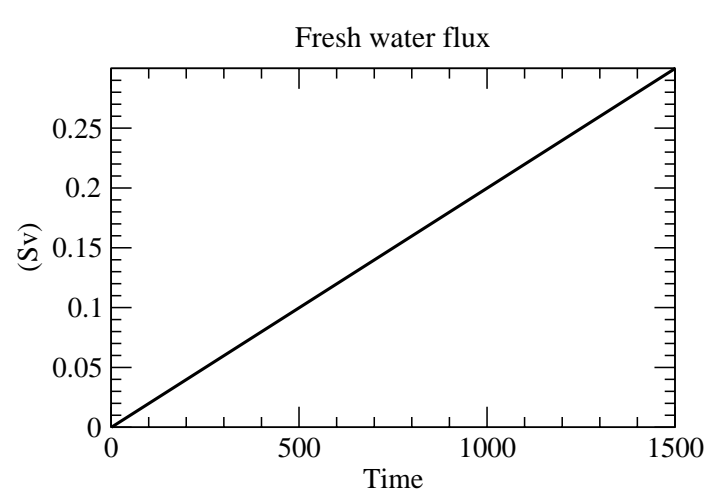

Fig. 2. Freshwater forcing in the North Atlantic in the perturbation scenario (left) and time evolution of the maximum of meridional overturning streamfunction below the Ekman layer in the Atlantic Ocean according to the selected model parameter sets in response to this perturbation (right). MOC is the absolute value. The colour code for the parameter sets is given in the figure.

(Fig. 1). This index represents the first digit that identifies the parameter sets.

The global annual mean surface temperature increase for the 9 climatic parameter sets ranges from 1.6 to $4.1^{\circ} \mathrm{C}$ after 1000 years (Table 2). Table 2 also provides the temperature increase after 70 years in the two times $\mathrm{CO}_{2}$ scenario (i.e. the transient temperature response or TCR), the effective climate sensitivity (Ceff) computed according to Gregory et al. (2002) and the equilibrium climate sensitivity (Equi). The temperature increase after 1000 years in our sensitivity experiment (CS) is already very close to the value of the effective climate sensitivity and the equilibrium climate sensitivity for the less sensitive parameter sets $(112,122,212$, and 222). Our parameters sets cover the likely range of climate sensitivity suggested by the IPCC (Randall et al., 2007), i.e. $2.1{ }^{\circ} \mathrm{C}$ to $4.4{ }^{\circ} \mathrm{C}$, based on GCM studies. It must be mentioned that, although LOVECLIM using parameter set 112 is not exactly the same as LOVECLIM1.0 used in Driesschaert et al. (2007), it shares many climatic features with this former version. In particular, its equilibrium sensitivity is rather low, i.e. $1.6^{\circ} \mathrm{C}$.

\subsubsection{Sensitivity to water hosing}

In a second sensitivity experiment (prefix E, suffix HYS, Table 1), freshwater is added in the North Atlantic $\left(20^{\circ}-50^{\circ} \mathrm{N}\right)$ with a linearly increasing rate of $2 \times 10^{-4} \mathrm{~Sv} \mathrm{yr}^{-1}$. This results in a freshwater perturbation of $0.1 \mathrm{~Sv}$ after 500 years, $0.2 \mathrm{~Sv}$ after 1000 years, and $0.3 \mathrm{~Sv}$ after 1500 years (Fig. 2, left). This simulation, which allows assessing the stability
Table 1. Summary of the major features of the different sensitivity simulations performed for each of the parameter sets $(x y z)$. More details are given in the text.

\begin{tabular}{ll}
\hline $\begin{array}{l}\text { Experiment } \\
\text { name }\end{array}$ & \\
\hline Exyz & $\begin{array}{l}\text { Pre-industrial equilibrium (E-simulation): } \\
\text { No volcanic forcing, GHG as in } 1750, \\
\text { TSI = Total Solar Irradiance }=1365 \mathrm{Wm}^{-2}\end{array}$ \\
\hline Exyz2CO & $\begin{array}{l}\text { Two times } \mathrm{CO}_{2} \text { scenario: } \\
\text { Starting from the corresponding E-simulation }\end{array}$ \\
& $\begin{array}{l}\text { Forcings as in E-simulations except for the atmospheric } \mathrm{CO}_{2} \\
\text { concentration (Fig. 1). }\end{array}$ \\
\hline ExyzHYS & $\begin{array}{l}\text { Water hosing simulation: } \\
\text { Starting from the corresponding E-simulation } \\
\text { Forcings as in the E-simulations except for a freshwater } \\
\text { perturbation applied in the North Atlantic (Fig. 2). }\end{array}$ \\
\hline ExyzTRA & $\begin{array}{l}\text { Transient simulation from } 1750 \text { to } 3000 \text { starting from the } \\
\text { corresponding E-simulation. } \\
\text { Forcings: orbital parameters, changes in concentration of GHGs } \\
\text { other than } \mathrm{CO}_{2} \text {, anthropogenic emissions of CO } \\
\text { and deforestation fluxes). }\end{array}$ \\
\hline
\end{tabular}

of the North Atlantic MOC, provides a good insight into the response of the ocean under perturbed conditions and can be compared with simulations performed with other models in similar conditions (e.g. Rahmstorf et al., 2005; Weber et al., 2007). The percentage of decrease in the maximum value of the meridional overturning streamfunction below the Ekman layer in the Atlantic Ocean after 1000 years in this water hosing experiment (at the time the perturbation reaches $0.2 \mathrm{~Sv}$ ) 


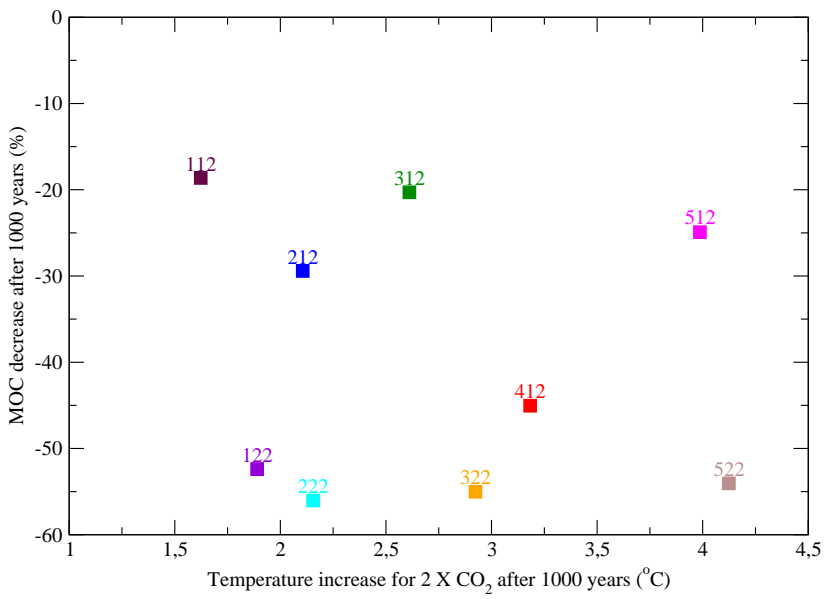

112122212222312322412512522

Fig. 3. Distribution of the model climatic parameter sets in the phase space (climate sensitivity, MOC sensitivity). The colour code for the parameter sets is also given below the figure.

is chosen to characterise the response of the model to this perturbation (MOC sensitivity). The MOC sensitivity is reflected in the second digit of the name of the experiments: 1 for a decrease in the maximum value of the meridional overturning streamfunction of less than $50 \%$, and 2 otherwise. LOVECLIM with parameter set 112, i.e. the closest to LOVECLIM 1.0 used in Driesschaert et al. (2007), simulates a $20 \%$ reduction in the meridional overturning streamfunction after 1000 years. This decrease ranges from 19 to $56 \%$ for the other parameter sets (Table 2).

Lastly, Fig. 3 confirms that the phase space (MOC sensitivity vs. climate sensitivity) of our set of experiments is rather homogeneously covered as required by our initial objective.

\subsubsection{Sensitivity of the carbon cycle}

We assess the sensitivity of the atmospheric $\mathrm{CO}_{2}$ level to the choice of carbon cycle parameters by performing a prognostic $\mathrm{CO}_{2}$ experiment (prefix E, suffix TRA, Table 1) for each of the three parameter sets. This transient simulation starts from an equilibrium state corresponding to the conditions prevailing in $1750 \mathrm{AD}$ (all years are in $\mathrm{AD}$ ). It runs until year 3000 and is constrained by changes in the Earth orbital parameters (Berger, 1978) and in concentrations of greenhouse gases (GHGs) except $\mathrm{CO}_{2}$. In addition, the model is forced by anthropogenic emissions of $\mathrm{CO}_{2}$, including both fossil fuel and deforestation fluxes. Over the historical period (1750-2000), the GHG concentrations (Houghton et al., 2001) and carbon emissions (Marland et al., 2003; Houghton, 2003) follow the historical records. From 2000 to 2100, we use the SRES A2 scenario (Houghton et al.,
Table 2. Main features of the model climate using different parameter sets (first column).

\begin{tabular}{lccccccc}
\hline & & & & \multicolumn{4}{c}{ Equilibrium } \\
\cline { 6 - 8 } Name & TCR & CS & Ceff & Equi & MOC & MOC & Ts \\
& $(1)$ & $(2)$ & $(3)$ & $(4)$ & $\begin{array}{c}\text { sensitivity } \\
(5)\end{array}$ & $(6)$ & $(7)$ \\
& & & & & & & \\
\hline & ${ }^{\circ} \mathrm{C}$ & ${ }^{\circ} \mathrm{C}$ & ${ }^{\circ} \mathrm{C}$ & ${ }^{\circ} \mathrm{C}$ & $\%$ & $\mathrm{~Sv}$ & ${ }^{\circ} \mathrm{C}$ \\
\hline 112 & 0.7 & 1.6 & 1.6 & 1.6 & -19 & 28.4 & 16.1 \\
122 & 0.8 & 1.9 & 1.9 & 2.0 & -52 & 17.3 & 15.8 \\
212 & 0.8 & 2.1 & 2.2 & 2.2 & -29 & 25.6 & 15.8 \\
222 & 0.9 & 2.2 & 2.2 & 2.3 & -56 & 21.5 & 15.6 \\
312 & 0.9 & 2.6 & 2.7 & 2.9 & -20 & 25.1 & 16.4 \\
322 & 1.0 & 2.9 & 3.1 & 3.3 & -55 & 20.9 & 15.7 \\
412 & 1.1 & 3.2 & 3.5 & 3.7 & -45 & 24.0 & 15.9 \\
512 & 1.5 & 4.0 & 4.4 & 4.5 & -25 & 23.9 & 16.1 \\
522 & 1.5 & 4.1 & 4.8 & 4.8 & -54 & 19.9 & 15.5 \\
\hline
\end{tabular}

(1) increase in global annual mean surface temperature after 70 years from the preindustrial equilibrium value in the doubling $\mathrm{CO}_{2}$ experiment;

(2) increase in global annual mean surface temperature after 1000 years from the preindustrial equilibrium value in the doubling $\mathrm{CO}_{2}$ experiment;

(3) the effective climate sensitivity according to Gregory et al. (2002) (see also Goelzer et al., 2010);

(4) the equilibrium response in global annual mean surface temperature is computed after 2000 years for the parameter sets 112, 122, 212, and 222; and after 3300 years for the parameter sets $312,322,412,512$, and 522;

(5) percentage of decrease in the meridional overturning streamfunction after 1000 years in the water hosing experiment;

(6) strength of the meridional overturning streamfunction in the North Atlantic (Sv) at equilibrium in the pre-industrial experiment;

(7) annual mean global surface temperature $\left({ }^{\circ} \mathrm{C}\right)$ at equilibrium in the pre-industrial experiment.

2001) for both carbon emissions and GHG concentrations. After 2100, concentrations of all GHGs (except $\mathrm{CO}_{2}$ ) are kept fixed to their 2100 values, while $\mathrm{CO}_{2}$ emissions from land use are set to zero and fossil fuel emissions decrease according to a bell-shaped curve so that they reach zero a few decades after 2200 (Fig. 4, top left).

The three carbon cycle parameter sets (Table 3) lead to contrasted responses of the atmospheric $\mathrm{CO}_{2}$ to the identical forcing (Fig. 4, top right). Maximal values of the atmospheric $\mathrm{CO}_{2}$ concentration differ by up to 169 ppmv between carbon sets 1 and 3 (Table 3). By year 2500, they still differ by 133 ppmv, i.e. a relative difference of about $11 \%$. With carbon cycle parameter sets 1 and 2, the land $\mathrm{CO}_{2}$ uptake outpaces the ocean uptake (Fig. 4, bottom left), while the reverse happens with carbon parameter set 3 .

The parameters related to the continental vegetation processes explain up to $87 \%$ of the difference in atmospheric $\mathrm{CO}_{2}$ response between the various experiments. On such time scales, changes in the rain ratio or in the export production within the ocean have a much smaller impact on the atmospheric $\mathrm{CO}_{2}$. The contribution of the rain ratio to 

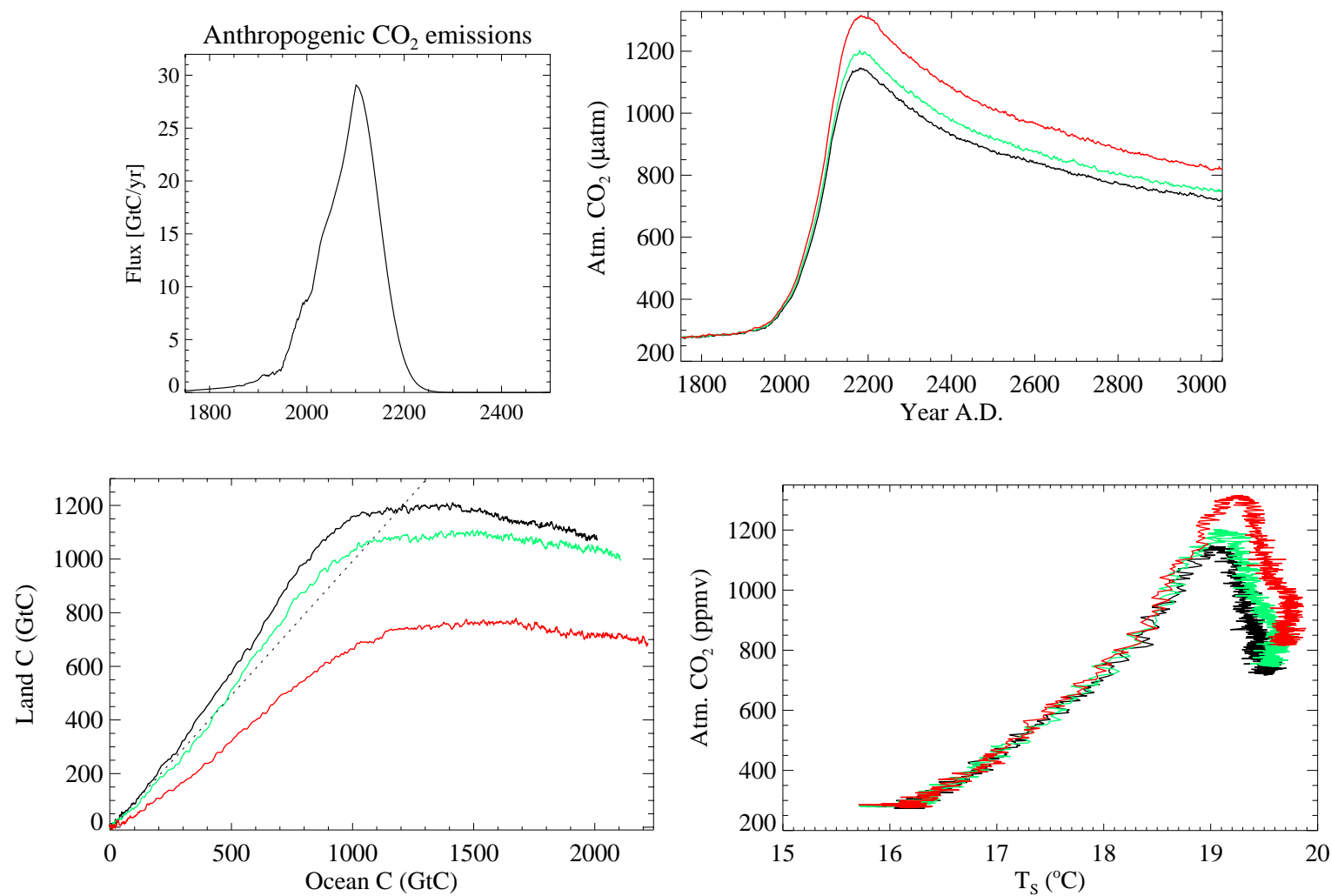

Fig. 4. $\mathrm{CO}_{2}$ emission scenario (top, left) used to assess the sensitivity of the carbon cycle to the different carbon cycle parameter sets (see description of the scenario in the text). It includes both fossil fuel emission and fluxes related to land use change. Evolution of the annual mean atmospheric $\mathrm{CO}_{2}$ concentration (ppmv) with time (top, right), terrestrial carbon inventory versus ocean carbon inventory (both in $\mathrm{GtC}$ ) (bottom, left), and atmospheric $\mathrm{CO}_{2}$ versus the global annual mean surface temperature (bottom, right) for the different carbon cycle parameter sets. The dashed line in the bottom left panel represents the 1:1 slope. Inventories are presented as anomalies with respect to the control run. The same colour code is used in each panel, i.e. black for parameter set 111, green for set 112, and red for set 113.

Table 3. Model parameter sets for the carbon cycle and their effect on the $\mathrm{CO}_{2}$ response. These parameters influence the continental vegetation fertilization effect ( $\beta g$ and $\beta t$; columns 2 and 3), the vertical flux of POM ( $\alpha_{\text {diatom }}$ and $\alpha_{\text {others }}$, columns 4 and 5), and the buildup of calcium carbonate shells ( $\Psi_{\mathrm{zoo}}$, column 6$)$. Columns 7 and 8 give the maximum value of the annual mean atmospheric $\mathrm{CO}_{2}$ concentration and its value at year 2500 from the transient simulations (see text) with the three carbon cycle parameter sets.

\begin{tabular}{lccccccr}
\hline $\begin{array}{l}\text { Carbon } \\
\text { parameter } \\
\text { set }\end{array}$ & $\beta g$ & $\beta t$ & $\alpha_{\text {diatom }}$ & $\alpha_{\text {others }}$ & $\Psi_{\text {zoo }}$ & \multicolumn{2}{c}{$\begin{array}{c}\text { Atm. } \mathrm{CO}_{2} \text { (ppmv) } \\
\text { Max }\end{array}$} \\
\hline 1 & 0.14 & 0.50 & -0.750 & -0.950 & 0.10 & 1146 & $\begin{array}{r}2500 \\
\mathrm{AD}\end{array}$ \\
2 & 0.36 & 0.36 & -0.858 & -0.858 & 0.22 & 1202 & 918 \\
3 & 0.14 & 0.22 & -0.648 & -0.648 & 0.22 & 1315 & 1010 \\
\hline
\end{tabular}

the maximum value of the atmospheric $\mathrm{CO}_{2}$ range is about $10 \%$, while changes in oceanic remineralization depth explain about three percent. Such small changes (a few ppmv) are within the variability produced by the model and cannot be ascertained yet. All together, the three parameter sets allow us to obtain a change in the carbon climate sensitivity (as defined in Frank et al., 2010) of the order of $7 \%$ (Fig. 4 bottom right).

The third digit in the experiment name refers to the carbon cycle parameter set with relatively low (1), medium (2), or high (3) changes in atmospheric $\mathrm{CO}_{2}$ in response to the same emission scenario.

\section{The climate of the last century}

\subsection{The simulations}

In this section, we study the climate simulated over the last century using all combinations of the different parameter sets (see Table 4 for the name of the different experiments). Our purpose is to quantify the ability of each parameter set to simulate climate changes over the last century, or over shorter periods, for which accurate observations are available. For the analysis of the simulated climate changes, we consider the average over an ensemble of five members in order to reduce the impact of internal variability. Each member consists 

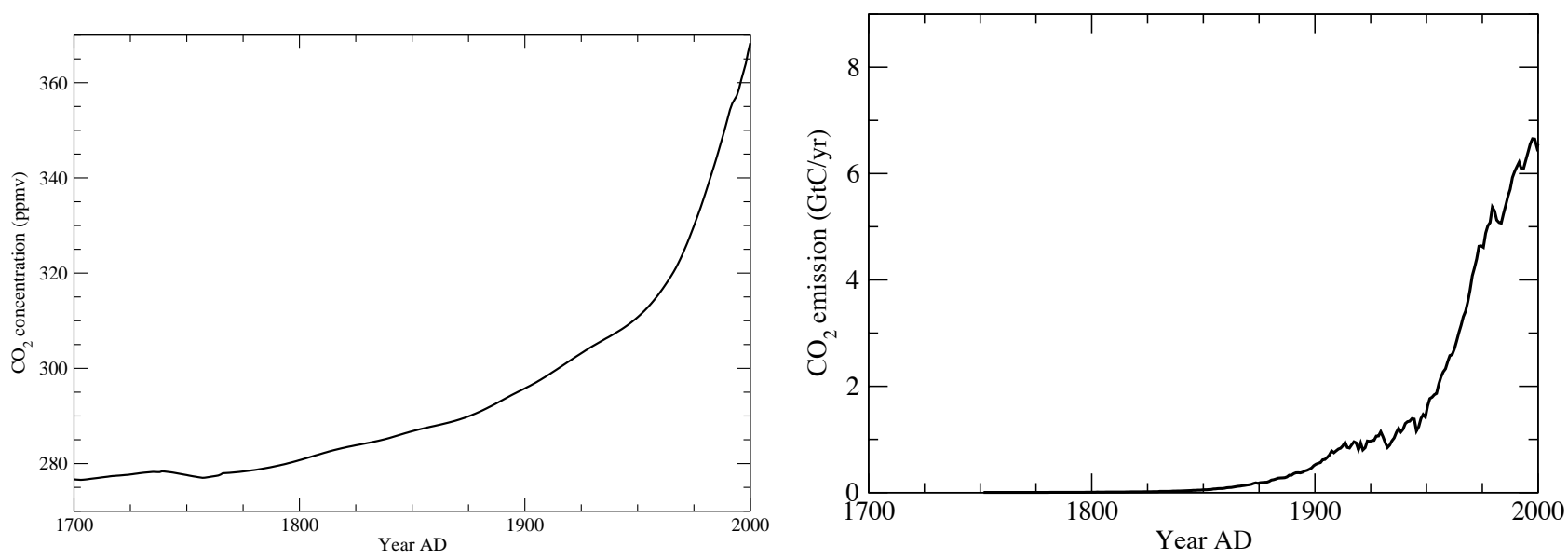

Fig. 5. Evolution over the last centuries (in year $\mathrm{AD}$ ) of the atmospheric $\mathrm{CO}_{2}$ concentration as prescribed in Conc (left) (Flückiger et al., 2002; Monnin et al., 2004; Siegenthaler et al., 2005; Meure et al., 2006; Enting et al., 1994; GLOBALVIEW-CO2, 2006); and the emission of $\mathrm{CO}_{2}\left(\mathrm{GtC} \mathrm{yr}^{-1}\right)$ from fossil fuel burning as prescribed in Efor simulations (right) (Marland et al., 2003).

Table 4. Summary of the major features of the different simulations of the last millennium/century. The three digits $x y z$ corresponds to the parameter set.

\begin{tabular}{|c|c|}
\hline $\begin{array}{l}\text { Experiment } \\
\text { name }\end{array}$ & \\
\hline MxyzS1Conc & $\begin{array}{l}\text { Simulation of the last millennium climate (transient simulation): } \\
\text { Starting from an equilibrium state at } 500 \mathrm{AD} \text {. } \\
\text { Forcings*: orbital parameters, land use changes, volcanic } \\
\text { activity, solar activity, changes in concentration of GHGs other } \\
\text { than } \mathrm{CO}_{2} \text {, sulphate aerosols ( } \mathrm{S} 1 \text { ), prognostic mode for } \\
\text { atmospheric } \mathrm{CO}_{2} \text { concentration }\left(\mathrm{CO}_{2} \text { emissions are }\right. \\
\text { considered as a forcing). }\end{array}$ \\
\hline MxyzS1Efor & $\begin{array}{l}\text { Simulation of the last millennium climate (transient simulation): } \\
\text { Starting from an equilibrium state at } 500 \mathrm{AD} \text {. } \\
\text { Forcings: orbital parameters, land use changes, volcanic activity, } \\
\text { solar activity, changes in concentration of GHGs other than } \mathrm{CO}_{2} \text {, } \\
\text { sulphate aerosols ( } \mathrm{S} 1) \text {, prognostic mode for atmospheric } \mathrm{CO}_{2} \\
\text { concentration }\left(\mathrm{CO}_{2} \text { emissions are considered as a forcing). }\right.\end{array}$ \\
\hline MxyzS2Conc & $\begin{array}{l}\text { Simulation of the last millennium climate (transient simulation): } \\
\text { Starting from an equilibrium state at } 500 \mathrm{AD} \text {. } \\
\text { Forcings: orbital parameters, land use changes, volcanic activity, } \\
\text { solar activity, changes in concentration of GHGs other than } \mathrm{CO}_{2} \text {, } \\
\text { sulphate aerosols ( } \mathrm{S} 2) \text {, diagnostic mode for atmospheric } \mathrm{CO}_{2} \\
\text { concentration }\left(\mathrm{CO}_{2} \text { concentration is considered as a forcing). }\right.\end{array}$ \\
\hline MxyzS2Efor & $\begin{array}{l}\text { Simulation of the last millennium climate (transient simulation): } \\
\text { Starting from an equilibrium state at } 500 \mathrm{AD} \text {. } \\
\text { Forcings: orbital parameters, land use changes, volcanic activity, } \\
\text { solar activity, changes in concentration of GHGs other than } \mathrm{CO}_{2} \text {, } \\
\text { sulphate aerosols ( } 2 \text { 2), prognostic mode for atmospheric } \mathrm{CO}_{2} \\
\text { concentration }\left(\mathrm{CO}_{2} \text { emissions are considered as a forcing). }\right.\end{array}$ \\
\hline
\end{tabular}

*The reader is referred to the text for a detailed explanation of the different simulations and forcings.

of a simulation of the climate of the last century starting in 1900 from the state at 1900 of a climate simulation of the last millennium performed with the same parameter set (Sect. 3 of the Supplement). The members of one ensemble differ only in their initial conditions. To do so, we have introduced a very small perturbation in the quasi-geostrophic potential vorticity the first day of the simulation, as described in Goosse et al. (2007).

The evolution of the atmospheric $\mathrm{CO}_{2}$ concentration is either diagnostic or prognostic. In the diagnostic mode (Conc), the atmospheric $\mathrm{CO}_{2}$ concentration is prescribed according to Enting et al. (1994) until 1990, and then according to GLOBALVIEW-CO2 (2006) (Fig. 5). For the prognostic mode (Efor), the atmospheric $\mathrm{CO}_{2}$ concentration is computed by forcing the model with emissions of $\mathrm{CO}_{2}$ from fossil fuel burning (Fig. 5, Marland et al., 2003). Both simulations also take into account land use changes related to human activities as in Goosse et al. (2005) (percentage of crops; Ramankutty and Foley, 1999; Pongratz et al., 2008). We assume that croplands replace only forests, as long as there is a forest fraction. Furthermore, desert and forest (except for the part replaced by crops) keep their original extent at year 500. This scenario was previously used in a model intercomparison exercise aiming at analysing the response of six EMICs, including ECBilt-CLIO-VECODE, to historical deforestation (Brovkin et al., 2006).

In addition to the atmospheric $\mathrm{CO}_{2}$ concentration, either prescribed or computed by the model (see above, Enting et al., 1994; GLOBALVIEW-CO2, 2006; Marland et al., 2003), the transient simulations are forced by the volcanic activity (Crowley, 2000), the solar activity (Muscheler et al., 2007), the Earth orbital parameter changes (Berger, 1978; Bretagnon, 1982), and changes in concentrations of GHGs other than $\mathrm{CO}_{2}$ (Prather et al., 2001; Houghton et al., 1990 and updates).

The effect of sulphate aerosols is accounted for through a modification in surface albedo, as suggested by Charlson et al. (1991) (scenario S1). For 150 years, human activities have increased the sulphate aerosol load in the troposphere (Houghton et al., 2001). However, the magnitude of 

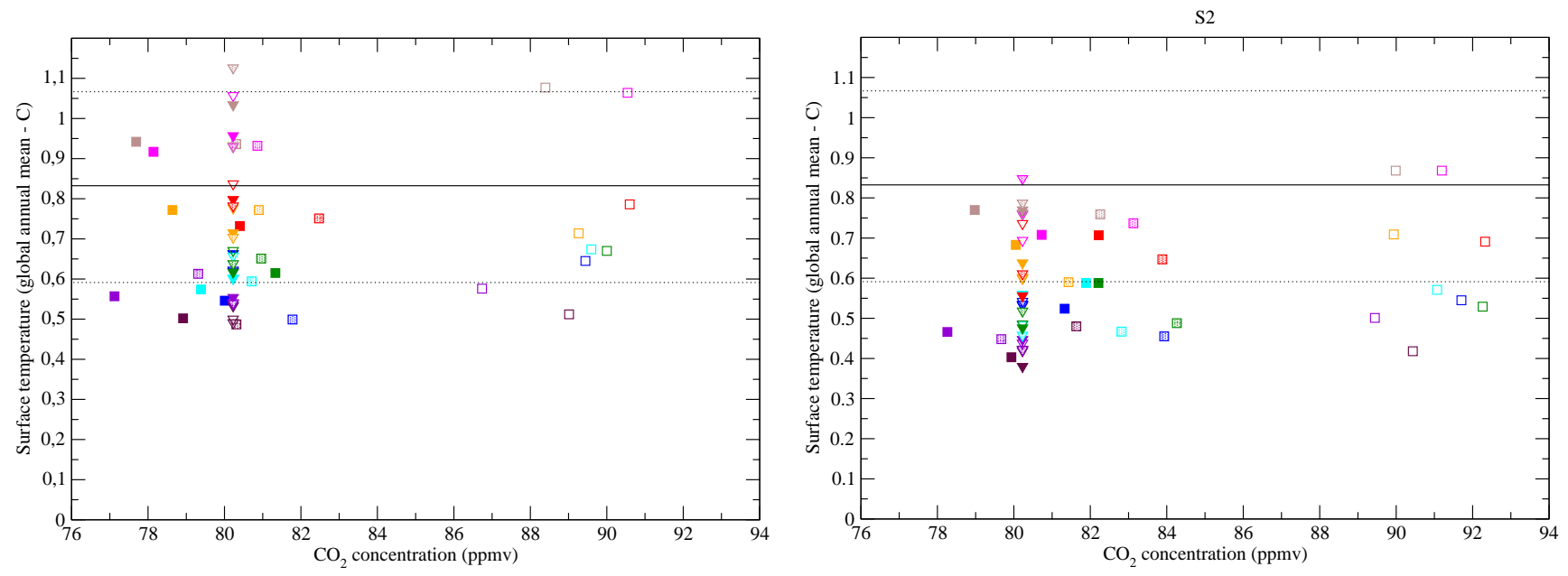

111221223132415152

Fig. 6. Global annual mean surface temperature increase with respect to increase in atmospheric $\mathrm{CO}_{2}$ concentration. The mean value increase is computed between the beginning of the 20th century (1901-1910) and the beginning of the 21st century (2000-2009). Values are averaged over five members of an ensemble. The left panel displays results for the S1 sulphate aerosol forcing. The sulphate aerosol forcing is doubled for the right panel (S2). The colour code refers only to the climatic parameter sets, i.e. the first two digits of the parameter set name. Full symbols are for carbon cycle parameter set 1 , half-filled symbols are for carbon cycle parameter set 2 , and empty symbols are for carbon cycle parameter set 3 . The full name of the parameter set is obtained by appending the number corresponding to the carbon cycle parameter set (i.e. 1, 2, or 3 according to the symbol) to the number corresponding to the climate parameter set given by the colour code. Squares (triangles down) correspond to Efor (Conc) simulations. The vertical line of triangles representing the increase in atmospheric $\mathrm{CO}_{2}$ concentration in the scenario used for Conc-simulations also represents the best observation-based estimate of this increase. The full black line indicates the temperature increase over the 20th century as reconstructed by Brohan et al. (2006) (i.e. $0.83^{\circ} \mathrm{C}$ ). The dashed lines are the upper and lower $95 \%$ uncertainty ranges.

its effect on the Earth climate is difficult to estimate. The radiative forcing computed by LOVECLIM for the present day with respect to the pre-industrial era related to the sulphate aerosol load is $-0.4 \mathrm{Wm}^{-2}$ in the reference situation (climatic parameter set 112). However, there is a large uncertainty in this quantity. IPCC AR4 (Forster et al., 2007) reported a direct radiative forcing due to sulphate aerosols of $-0.40 \pm 0.2 \mathrm{Wm}^{-2}$. The overall aerosol direct radiative forcing (i.e. radiative forcing values associated with several aerosol components) was estimated to $-0.50 \pm 0.40 \mathrm{Wm}^{-2}$. In addition to a direct effect, aerosol particles also affect the formation and properties of clouds. IPCC AR4 gives a median value of $-0.70 \mathrm{Wm}^{-2}$ for the cloud albedo radiative forcing due to aerosol influence on clouds. Therefore, we decided to perform a second set of simulations for which the radiative forcing related to sulphates is doubled, $-0.8 \mathrm{Wm}^{-2}$ in the reference situation (climatic parameter set 112) (scenario S2).

\subsection{Results}

\subsection{1 $\mathrm{CO}_{2}$ concentration}

The comparison of the simulated time evolution of the atmospheric $\mathrm{CO}_{2}$ concentration over the last century with data shows that some parameter sets display a poorer agreement than others (Fig. 6). In particular, the simulated increase in $\mathrm{CO}_{2}$ concentration obtained with carbon cycle parameter set 3 is of the order of $10 \mathrm{ppmv}$ larger than in the corresponding observations over the 20th century. In contrast, the simulated increase in atmospheric $\mathrm{CO}_{2}$ concentration remains close to the measured one for carbon cycle parameter sets 1 and 2 .

Similar conclusions can be reached by analysing the rate of increase in $\mathrm{CO}_{2}$ concentration over different periods. Between 1959 and 2008, it varies between 1.35 and $1.47 \mathrm{ppmv} \mathrm{yr}^{-1}$ for carbon cycle parameter sets 1 and 2, with the nominal (S1) sulphate forcing. Furthermore, the rate is higher with carbon cycle parameter set $3\left(\sim 1.58 \mathrm{ppmv} \mathrm{yr}^{-1}\right)$ as well as when the $\mathrm{S} 2$ sulphate forcing is applied (by about $0.03 \mathrm{ppmv} \mathrm{yr}^{-1}$ ). It is in reasonable agreement with the corresponding value in the Mauna Loa record (NOAA ESRL, 2009) of $1.44 \mathrm{ppmv} \mathrm{yr}^{-1}$. A comparison with another 


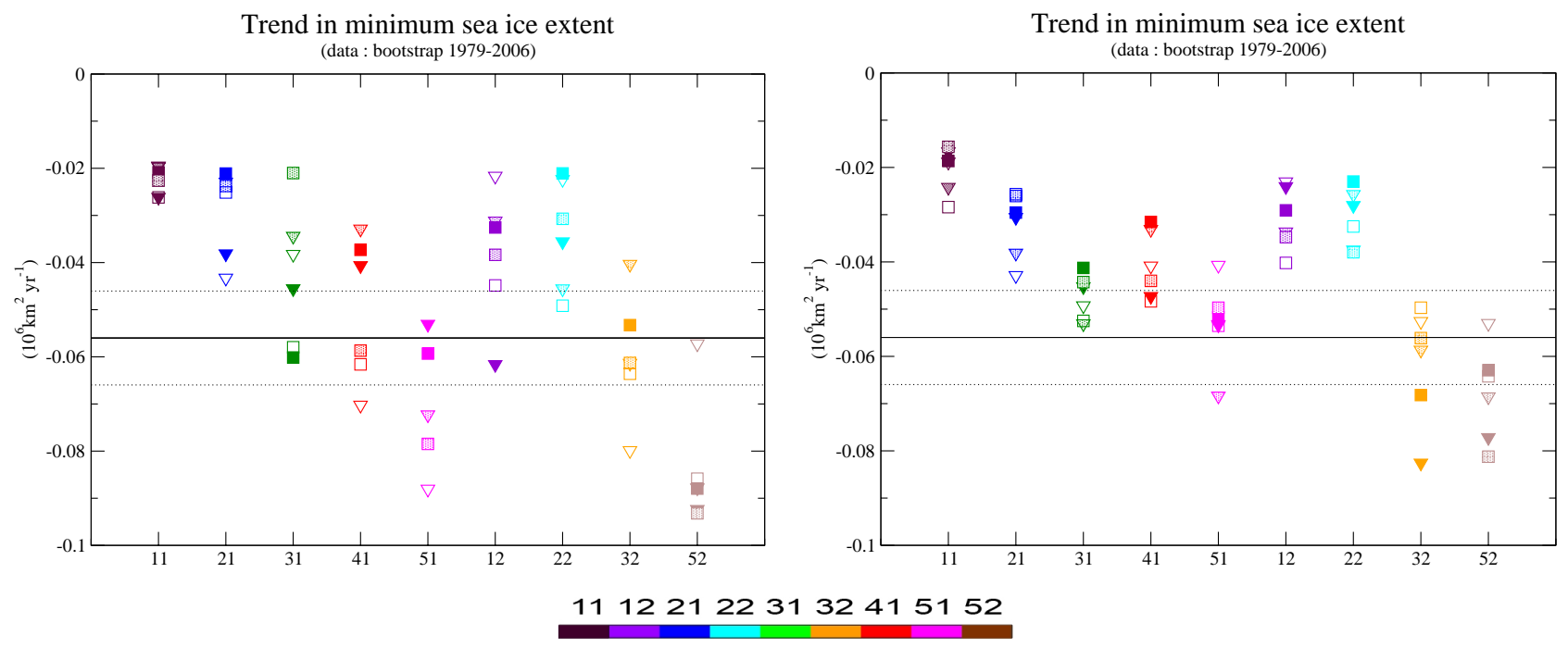

Fig. 7. Trend in minimum Northern Hemisphere sea ice extent between 1979 and 2006. X-axis is for the climate sensitivity, either for S1 (left) or S2 (right) sulphate aerosol forcing. The colour code refers only to the climatic parameter sets, i.e. the first two digits of the parameter set name. Full symbols are for carbon cycle parameter set 1 , half-filled symbols are for carbon cycle parameter set 2 , and empty symbols are for carbon cycle parameter set 3 . The full name of the parameter set is obtained by appending the number corresponding to the carbon cycle parameter set (i.e. 1, 2 or 3, according to the symbol) to the number corresponding to the climate parameter set given by the colour code. Squares (triangles down) correspond to Efor (Conc) simulations. The full black line indicates the minimum sea ice extent as reconstructed by Comiso and Nishio (2008). The dashed line represents the uncertainty related to the variability in the data (one standard deviation on the slope).

observation series (Enting et al., 1994; GLOBALVIEWCO2, 2006) over the time interval 1979-2005 yields similar conclusions. For this period, the rate of increase in $\mathrm{CO}_{2}$ concentration varies between 1.48 and $1.62 \mathrm{ppmv} \mathrm{yr}^{-1}$ for carbon cycle parameter sets 1 and 2, respectively, with the $\mathrm{S} 1$ sulphate forcing. It is higher with the carbon cycle parameter set 3 (between 1.71 and $1.79 \mathrm{ppmv} \mathrm{yr}^{-1}$ ). Here we obtain a larger $\mathrm{CO}_{2}$ increase for a smaller temperature increase, which can be considered as a negative $\mathrm{CO}_{2}$-climate feedback. In other words, the net feedback (Friedlingstein et al., 2003), which is the global warming amplification, is slightly smaller than one.

\subsubsection{Surface temperature}

The increasing trend in global annual mean surface temperature computed from HadCRUT3 time series (Brohan et al., $2006)$ is $0.0168^{\circ} \mathrm{C} \mathrm{yr}^{-1}$ over the last 35 years (1979-2005) and $0.0071^{\circ} \mathrm{C} \mathrm{yr}^{-1}$ over the last century (1901-2005). Some parameter sets lead to an underestimate of this increasing trend. This is, for example, the case for the climatic parameter sets 11,21 , and 22, especially with the $\mathrm{S} 2$ sulphate forcing; while other climatic parameter sets yield an overestimate of this trend, e.g. 51 and 52, especially with the S1 sulphate forcing.

\subsubsection{Minimum sea ice extent}

Most of the simulations, either with S1 or S2 sulphate aerosol forcing, experience a too small decrease in Northern Hemisphere minimum sea ice extent between 1979 and 2006 compared to observations (Fig. 7). This is especially the case for those simulations with low climate sensitivity (climatic parameter sets 11, 12, 21, 22). For higher sensitivities, the type of simulation (Efor or Conc), the sulphate aerosol load (S1 or S2) as well as the sensitivity to the carbon cycle may play a role in the simulated trend. However, larger sulphate aerosol concentrations do not systematically lead to lower or higher trend in Northern Hemisphere minimum sea ice extent.

\subsubsection{Oceanic variables}

Most of the simulations overestimate the estimated warming of the global ocean in the $700 \mathrm{~m}$ upper layer over the last 50 years (Levitus et al., 2009) when the S1 sulphate forcing is used (Fig. 8). This overestimation is strongly reduced for S2 sulphate forcing. Indeed, in that case, only the simulations with high climate sensitivity (climatic parameter sets 51,52 , as well as 32 and 41 for some experimental setups) exhibit an ocean heat content increase significantly larger than in the real world.

The modelled ocean circulation does not experience major changes during the last century. Over this period, all the simulations show a reduction of less than $4 \mathrm{~Sv}$ in the 

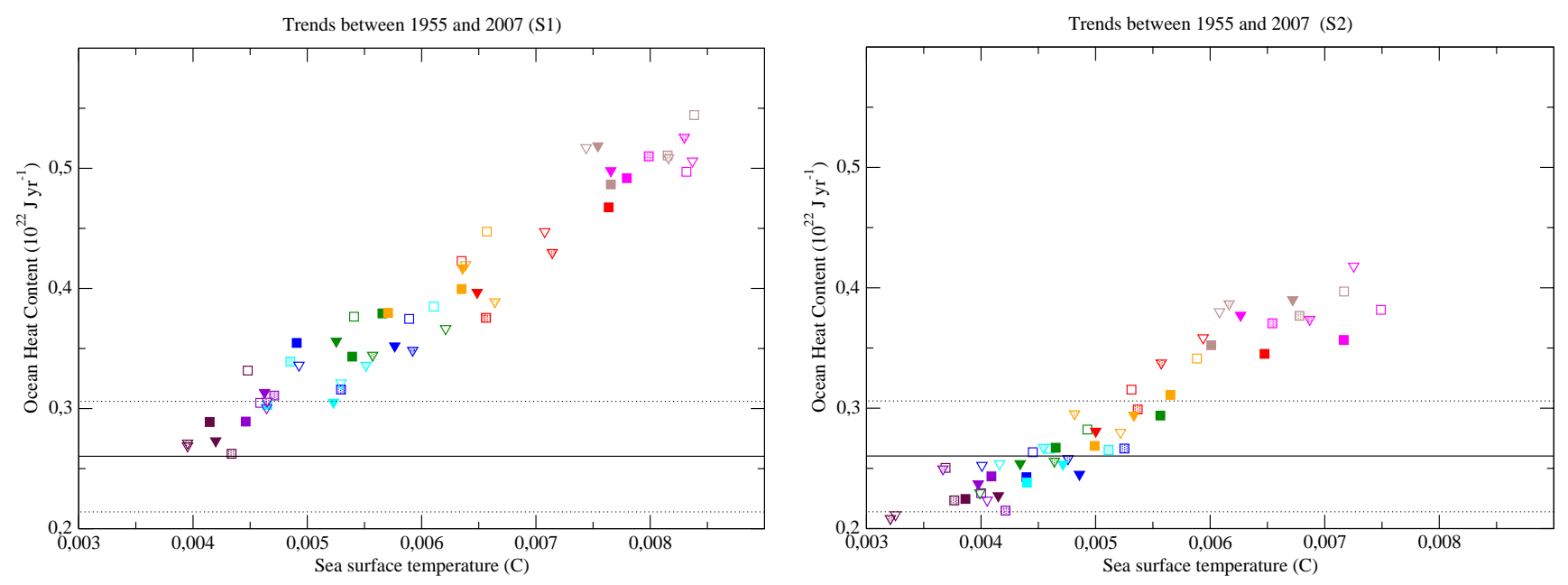

111221223132415152

Fig. 8. Trend in ocean heat content in the upper $700 \mathrm{~m}\left(10^{22} \mathrm{~J} \mathrm{yr}^{-1}\right)$ wrt trend in sea surface temperature $\left(\mathrm{C} \mathrm{yr}^{-1}\right)$. Each symbol corresponds to one simulation, either for S1 (left) or S2 (right) sulphate aerosol forcing. Trends are computed as the slope of the regression line through the annual values between 1955 and 2007. The colour code refers only to the climatic parameter sets, i.e. the first two digits of the parameter set name. Full symbols are for carbon cycle parameter set 1, half-filled symbols are for carbon cycle parameter set 2, and empty symbols are for carbon cycle parameter set 3 . The full name of the parameter set is obtained by appending the number corresponding to the carbon cycle parameter set (i.e. 1, 2, or 3 according to the symbol) to the number corresponding to the climate parameter set given by the colour code. Squares (triangles down) correspond to Efor (Conc) simulations. The full black line represents the trend computed from observation (Levitus et al., 2009). The dashed line represents the uncertainty related to the variability in the data (one standard deviation on the slope of the linear regression through observation.

strength of North Atlantic MOC (AMOC) for S1 sulphate aerosol forcing (3 Sv; S2 sulphate aerosol forcing) (Fig. 9), although there is a large spread in the maximum intensity of the AMOC depending on the parameter sets (between 17 and $28 \mathrm{~Sv}$ in 1900 depending on the parameter).

\subsubsection{Discussion}

The surface temperature changes simulated over the last century obviously depend on the climate sensitivity. The parameter sets corresponding to the lowest climate sensitivity (such as climatic parameter sets 11,21, and 22) lead to small temperature changes over the last century and those with the largest climate sensitivity (e.g. climatic parameter sets 51 and 52) lead to a large temperature increase over the last century. Moreover, using a larger sulphate aerosol forcing tends to shift the simulated temperature increase over the last century towards smaller values because of the radiative cooling effect of those aerosols. Still, the discrepancy between simulated global annual mean surface temperature and observations remains small (within one standard deviation) in many cases.

Moreover, although the deviation from observations of the simulated atmospheric $\mathrm{CO}_{2}$ concentration is of the order of 10 ppmv over the 20th century (Fig. 6) for carbon cycle parameter set 3 , this discrepancy is not large enough to drive the surface temperature towards larger values than for carbon cycle parameter set 1 or 2 . Therefore, most of the simulations with carbon cycle parameter set 1 or 2 remain close to temperature observations, while those using carbon cycle parameter set 3 display only a small disagreement.

The simulations performed here display an approximately linear relationship between the increase in the upper ocean heat content and the increase in sea surface temperature (Fig. 8), i.e. when temperature increases, in particular sea surface temperature, the ocean captures more heat. We speculate that a too large ocean heat uptake leads to a deficit in energy available at the ocean surface for melting the sea ice simulated with several parameter sets.

The relationship between increase in atmospheric $\mathrm{CO}_{2}$ concentration and the North Atlantic MOC was studied in several GCMs and EMICs (including LOVECLIM) (Gregory et al., 2005). These authors performed partially coupled integrations to evaluate the influence of heat and freshwater in each of the models. They pointed out that heat flux changes generally contribute more than freshwater flux changes to weakening the MOC for all models. We also find an approximately linear relationship between the sea surface temperature and the North Atlantic MOC intensity (Fig. 9). In contrast, there is no clear relationship between the change in upper ocean heat content and MOC sensitivity. Therefore, the climate sensitivity has a stronger effect on the ocean over 

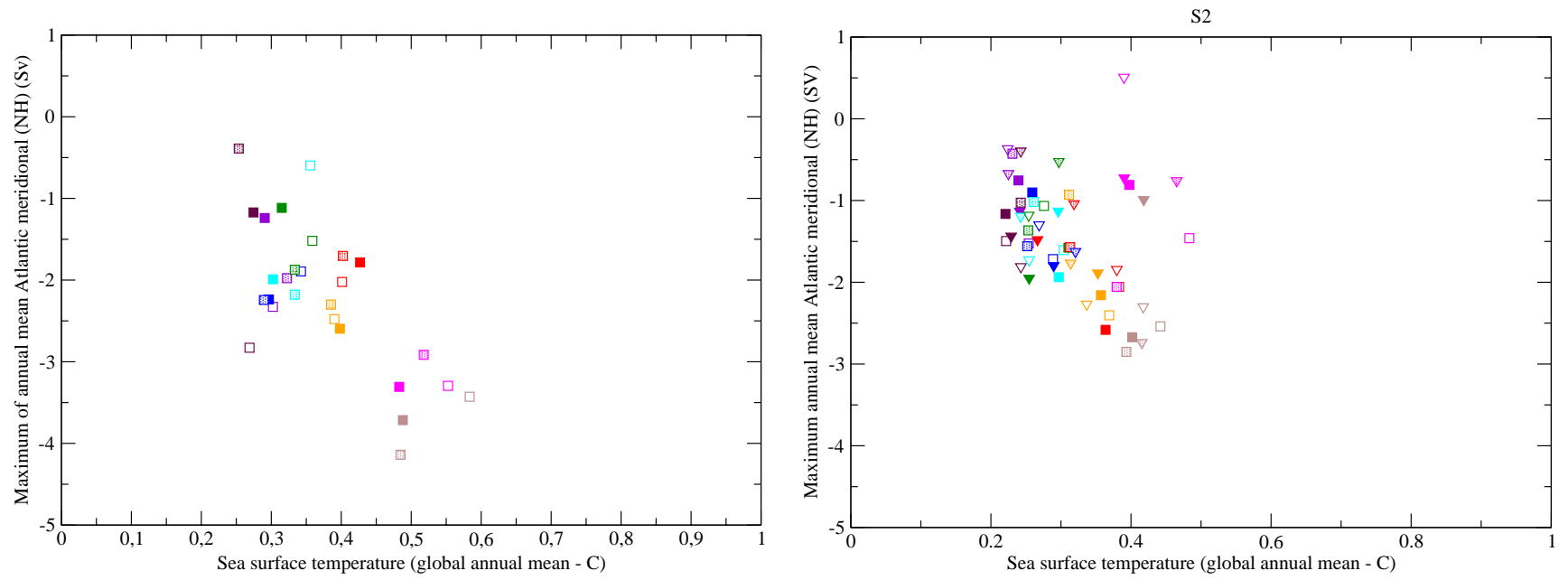

111221223132415152

Fig. 9. Change in the maximum of the North Atlantic meridional overturning streamfunction (Sv) wrt change in the global annual mean sea surface temperature $\left({ }^{\circ} \mathrm{C}\right)$. The colour code refers only to the climatic parameter sets, i.e. the first two digits of the parameter set name, either for S1 (left) or S2 (right) sulphate aerosol forcing. Squares (triangles down) correspond to Efor (Conc) simulations. Full symbols are for carbon cycle parameter set 1 , half-filled symbols are for carbon cycle parameter set 2, and empty symbols are for carbon cycle parameter set 3 .

the 20th century than MOC sensitivity. In other words, even though we selected parameter sets in a large phase space, the ocean is responding more to the atmospheric forcing than to its intrinsic characteristics over the last few decades. The initial states of the ocean, that are different depending on the parameter sets, do not induce large changes in the upper ocean heat content either. Of course we should verify that this conclusion, drawn only from LOVECLIM simulations, is robust for both other models and other forcings.

\subsection{Performance of the parameter sets}

Although none of the selected parameter sets is able to yield a climate simulation in the range of observations for all the variables examined, some parameter sets perform better than others. The purpose of this section is to characterise (and rank) them according to their performance. Therefore, we designed a metric that quantifies the ability of a simulation (i.e. a given parameter set and a given configuration) to simulate the observed climate change over the last century. This metric is a measure of how well the simulated trends fit the observationally-based estimates of several climatic indicators during the 20th century. Indeed, as long as we are interested in climate change, it is more important to simulate a correct evolution of the variables, rather than a correct value of any time. The metric is based on the same variables as those discussed in the previous section (global annual mean surface temperature, atmospheric $\mathrm{CO}_{2}$ concentration, minimum sea ice extent in the Northern Hemisphere, and ocean heat content of the upper $700 \mathrm{~m}$ of the global ocean). The design of the metric is explained in Sect. 4 of the Supplement. Each simulation (i.e. given parameter sets, sulphate forcing, and setup) receives a score. None of the simulations received the maximum score of four (Conc) or six (Efor) points. The best simulations received a total score of three (Conc) and four (Efor) points (Fig. 10).

Simulations with the carbon cycle parameter set 3 do not properly reproduce the observed atmospheric $\mathrm{CO}_{2}$ increase. Still, the deviation from observations remains less than 10 ppmv over the last 50 years and this does not prevent simulation of temperature increase in agreement with observations. Moreover, none can simulate simultaneously a correct time evolution for the ocean heat content in the upper $700 \mathrm{~m}$ and for the Northern Hemisphere sea ice extent. Goosse et al. (2007) studied the time evolution of the Northern Hemisphere sea ice extent in transient simulations from $8 \mathrm{kyr} B \mathrm{PP}$ to $2100 \mathrm{AD}$, starting from an equilibrium state at $8 \mathrm{kyr} \mathrm{BP}$, and using five parameter sets corresponding to 112,212 , 312,412 , and 512. They showed that, compared to observations covering the second half of the 20th century, parameter sets 112 and 212 seriously underestimate the decline in summer sea ice extent, while parameter set 312 slightly underestimates it. Therefore, Goosse et al. (2007) concluded that parameter sets 112 and 212 are incompatible with the observed record. This is well in line with our analysis.

The aerosol forcing scenario (S1 or S2) has a strong impact on the skill of a parameter set to reproduce the climate change for a given variable. For example, more parameter sets perform well in reproducing the ocean heat content trend under S2 than S1. On the contrary, the temperature increase 

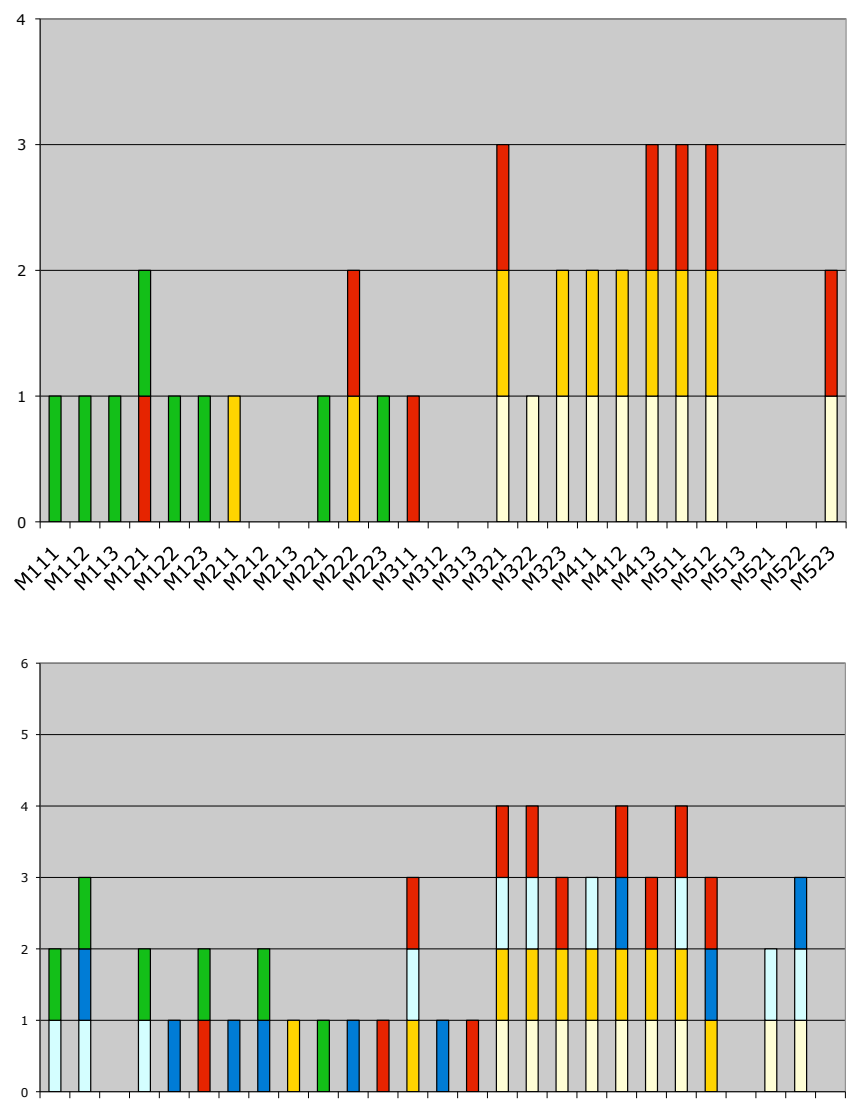

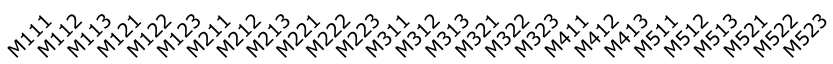
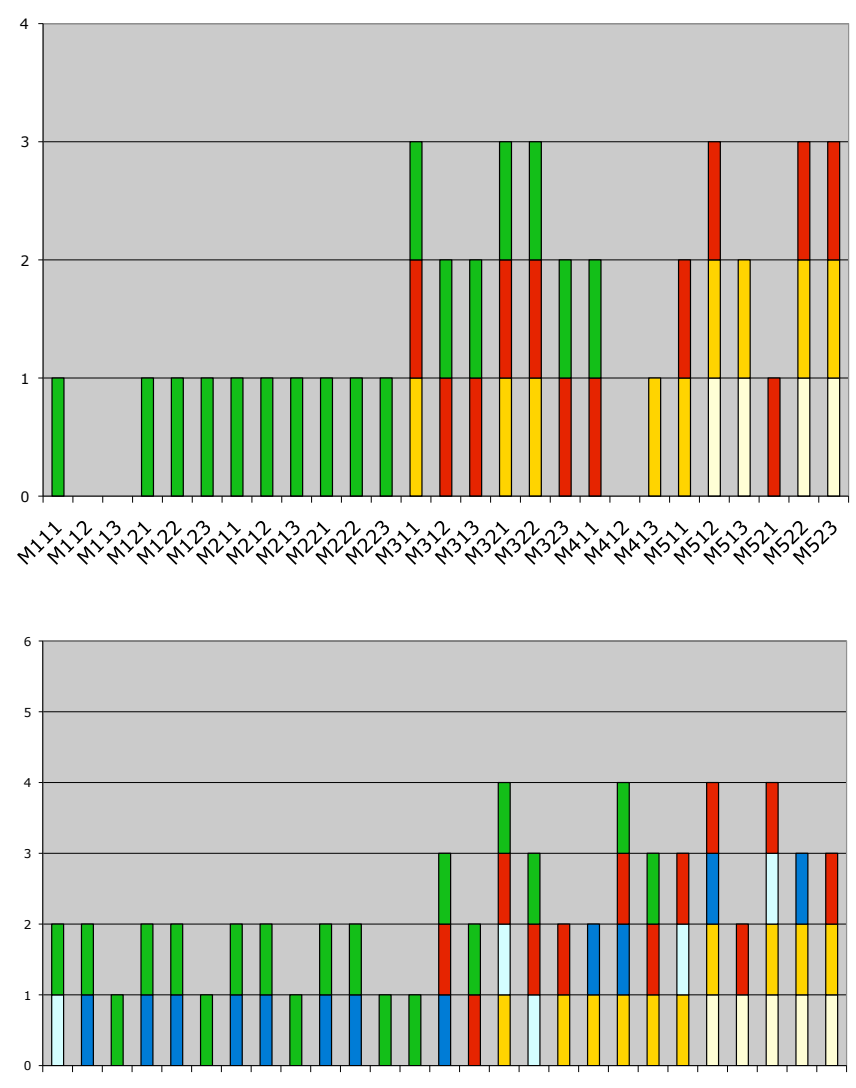

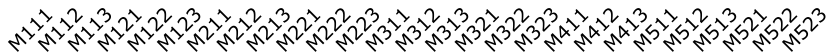

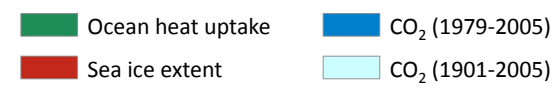

$\square$ Ts (1979-2005)
$\square$ Ts (1901-2005)

Fig. 10. Summary of the performance of the Conc (top) and Efor (bottom) simulations to reproduce the observed trend of the time evolution for different climate variables for each parameter set under S1 (left) and S2 (right) sulphate aerosol forcings. The variables and the time intervals are described in Sect. 4 of the Supplement. The x-axis lists all the parameter sets. Colour bars indicate the variables (see colour code) simulated with a good skill (according to our metric), i.e. $R$ above the threshold (see text). A single colour bar is used for sea ice and upper ocean heat content. Ts stands for global annual mean surface temperature either over the interval 1901-2005 or 1979-2005. CO 2 is for atmospheric $\mathrm{CO}_{2}$ concentration either over the time interval 1901-2005 or 1979-2005. Sea ice extent trend is computed either between 1979 and 2006 or 1979 and 2007. Trend in ocean heat content in the upper $700 \mathrm{~m}$ of the ocean is computed over either the time interval 1955-2007 or 1950-2003. See also the Supplement for references.

over the 20th century and the last decades is better simulated with S1 than S2.

When atmospheric $\mathrm{CO}_{2}$ concentration is prescribed (Conc), most of the parameter sets, except those with the lowest climate sensitivity, are able to reproduce the observed temperature trend over the 20th century. The trend in upper ocean heat content remains within $66 \%$ of the median of the deviation from observations for the low climate sensitivity parameter sets when $\mathrm{S} 1$ aerosol forcing is used. It is also true for a few more parameter sets when S2 aerosol forcing is used.

Generally speaking, simulations with high climate sensitivity (climatic parameter sets $32,41,51,52$ ) have a better global score than simulations with low climate sensitivity. Amongst the simulations ranking the highest (i.e. a final mark of 3 for Conc and 4 for Efor), parameter set 321 is the only one performing well for both Conc and Efor, as well as for both S1 and S2 sulphate aerosol forcings. Moreover, other parameter sets $(322,511,512)$ also display good performance for both Conc and Efor, but only either for S1 or S2 sulphate aerosol forcing.

Parameter set 321 performs particularly well. Its only major weakness is the simulation of the evolution of the upper ocean heat content in the case of S1 sulphate forcing and long-term temperature (and $\mathrm{CO}_{2}$ ) in the case of $\mathrm{S} 2$ sulphate aerosol forcing. Simulating an increase of the upper ocean 
heat content in line with observations is also a major problem for the other "good" parameter sets (except for parameter set 322 under Conc-setup with S2 sulphate aerosol forcing).

The difficulty of simulating properly the increase in the upper ocean heat content is a rather general feature of all the simulations, especially those with high climate sensitivity. The parameter sets selected as having a "good skill" to reproduce the 20th century climate trend are those allowing a good simulation of the atmospheric temperature increase of the last century and the last decades of that century. However, their skill in reproducing the increase in the upper ocean heat content is much poorer. Conversely, the parameter sets leading to a good representation of the trend in upper ocean heat content lead to a too weak global warming over the last century and last decades.

It is worth mentioning that a good skill over the last decades, as measured by the metric, does not guarantee a good skill over the entire last century. This is particularly true for the temperature changes for most of the parameter sets. On the other hand, as already underlined, most of the parameter sets do not allow accurately capturing the $\mathrm{CO}_{2}$ trend over the last decades, although the deviation is small. Moreover, Efor experiments have two additional degrees of freedom compared to Conc. In Efor, the atmospheric $\mathrm{CO}_{2}$ is prognostic as well as the carbon emissions resulting from the land-use changes, while, in Conc, the latter flux is imposed and is the same for all climatic parameter sets. Since different climatic parameter sets lead to different vegetation distributions, the $\mathrm{CO}_{2}$ emissions in Efor may differ among parameter sets. This results in different atmospheric $\mathrm{CO}_{2}$ levels, which in turn result in a different vegetation response since the latter also depends on $\mathrm{CO}_{2}$ levels through the fertilization term. Lower atmospheric $\mathrm{CO}_{2}$ concentration generates a weaker carbon emission (and vice versa). Indeed, the emission is calculated on the basis of the potential growth of trees, which is favoured by higher atmospheric $\mathrm{CO}_{2}$ concentrations. This may explain the change in performance between Conc and Efor experiments, such as for parameter 412 (with S2 forcing), which is very poor in the Conc-simulation, while it performs well in the Efor-simulation.

For each variable, the metric gives only a binary result, either good or bad agreement between simulation and data. However, the discrepancy may be weak or strong, even for parameter sets that exhibit a good overall skill. For example, parameter set 321 (under Conc-setup), which has a good global score, displays a very strong disagreement for the upper ocean heat content with $\mathrm{S} 1$ sulphate aerosol forcing. Conversely, parameter set 211 displays a poor global skill, although the disagreement between model and data is only weak for most of the variables. This highlights how critical the choice of the threshold value is that separates between "good" and "poor" agreement.

\section{Conclusions}

This work is part of a study that aims at the quantification of uncertainties in modelling experiments used in climate change projections. Different approaches could be used, such as using various models or different external forcings. Here, we used different values for selected parameter sets of a particular model (LOVECLIM). In this way, we create alternative versions of the model. More precisely, we selected 27 parameter sets (nine climatic parameter sets and three carbon cycle parameter sets) according to their ability (1) to cover a large range of potential climate behaviours over the next millennium, and (2) to properly simulate the major features of the present-day climate. This small and manageable number of parameter sets was selected because: (i) we broadly knew the individual effect of each parameter on the modelled climate; (ii) we knew that each parameter set would lead to realistic simulated present-day climate; and (iii) we knew for sure that they would yield a range of different model behaviours according to the model sensitivity to an increase in atmospheric $\mathrm{CO}_{2}$ concentration, to its response to a freshwater hosing, and to its sensitivity to carbon cycle.

We designed a metric in order to quantify the skill of the different parameter sets to reproduce the climate change over the last decades of the 20th century, with a specific focus on global annual mean surface temperature, atmospheric $\mathrm{CO}_{2}$ concentration, minimum Northern Hemisphere sea ice extent, and upper ocean heat content. Indeed, when designing this metric, we had in mind to simulate the evolution of the ice sheets and sea level in the future (Goelzer et al., 2010), and our metric is therefore based on variables chosen in line with this final purpose. However, another set of variables, for example giving more weight to the ocean or the ice sheet component of the system, could give rise to a slightly different conclusion about the skill of the parameter sets.

We then rank the model versions according to their ability to simulate the past climate changes. None of the parameter sets are able to reproduce the observed trend of all the chosen key variables of the climate system (e.g. surface temperature, atmospheric $\mathrm{CO}_{2}$ concentration, sea ice extent, ocean heat content). Nevertheless, parameter sets 321, 322, 511 , and 512 display good performance for more than one simulation setup (i.e. S1Conc, S2Conc, S1Efor or S2Efor). Moreover, parameter sets 321 and 322 are able to simulate a relatively good agreement for surface temperature and ocean heat uptake trends. Other parameter sets (e.g. 311, 412, 521, $522,523)$ have only a slightly less good score. Therefore, we can use this work to reduce the number of parameter sets, keeping only the best ones in simulating climate with LOVECLIM and the model will still cover a wide range of realistic responses to given forcings. Alternatively, we can keep them all, although it must then be kept in mind that some yield a less realistic behaviour, at least for some components of the climate system. This second alternative allows coverage of more extreme cases that must be assessed in light of 
the simulation of past climates. Another possibility to be explored is to give a weight to each simulation, with less weight given to a simulation performed with a low skill parameter set. However, in that case, additional simulations should be performed and more variables should be included in the design of the metric.

We also noted that the climate sensitivity seems to have a stronger impact on the simulated climate, and even on the ocean behaviour, than the mean ocean state or the model response to a freshwater hosing. Of course, this conclusion applies for LOVECLIM, within the framework of the forcing and parameter study performed here. It should be checked whether it is robust for other models, other parameterisations, or other forcings.

By using one single model, we did not address the structural uncertainty (related to the choice made during the buildup of the model) that can also be a major source of discrepancy between model results. Ideally, both types of uncertainty should be addressed together, in addition to the ones associated with the forcing, but this long-term goal is clearly outside the scope of the present study. Even though we tested a large number of values for different key physical parameters of the model (many more than finally used in this study), we were unable to clearly solve identified drawbacks as underlined by some systematic biases present with all the parameter sets, such as the strong ocean heat uptake. Therefore, we are convinced that further tuning will be relatively ineffective to improve the model behaviour to simulate past climates, at least for some variables and in some regions. Hence, improving the model probably requires improving the physics rather than (or in addition to) improving the values of its parameters. Given those biases, it is clearly inappropriate for the ensemble we have built to be used for making sound estimates of uncertainty in climate predictions/projections at the decadal-to-century time scale. Nevertheless, we feel that this ensemble is diverse and realistic enough to test the effect of the differences in model sensitivity, which are poorly constrained and vary largely among GCMs and EMICs, on the long-term response of the Earth's system to the greenhouse gas forcing. In Goelzer et al. (2010), for instance, it has been utilized to investigate the impact of fully interactive Greenland and Antarctic ice sheets under greenhouse warming conditions on the climate sensitivity at the millennial time scale.

\section{Supplementary material related to this article is available online at: http://www.clim-past.net/7/511/2011/ cp-7-511-2011-supplement.pdf.}

Acknowledgements. The Belgian Federal Science Policy funded this research within its Research Programme on Science for a Sustainable Development (SD/CS/01). We thank Pierre-Yves Barriat for helping in developments of the computer code. H. Goosse is Research Associate with the Fonds National de la Recherche Scientifique (Belgium). Computer time was partly made available by UCL (Fonds spéciaux de recherche) and FNRS (Fonds de la recherche fondamentale collective) FRFC N 2.4502.05: "Simulation numérique. Application en physique de l'état solide, océanographie et dynamique des fluides". We thank Julia C. Hargreaves and two anonymous reviewers who provided helpful comments on the manuscript. We also thank the CISM-team.

Edited by: V. Rath

\section{References}

Berger, A.: Long-term variations of daily insolation and Quaternary climatic changes, J. Atmos. Sci., 35(12), 2362-2367, 1978.

Bertrand, C., Loutre, M. F., Crucifix, M., and Berger, A.: Climate of the last millennium: a sensitivity study, Tellus A, 54, 221-244, 2002.

Braconnot, P., Loutre, M. F., Dong, B., Joussaume, S., and Valdes, P.: How the simulated change in monsoon at $6 \mathrm{kaBP}$ is related to the simulation of the modern climate: results from the Paleoclimate Modeling Intercomparison Project, Clim. Dynam., 19, 107-121, 2002.

Braconnot, P., Otto-Bliesner, B., Harrison, S., Joussaume, S., Peterchmitt, J.-Y., Abe-Ouchi, A., Crucifix, M., Driesschaert, E., Fichefet, Th., Hewitt, C. D., Kageyama, M., Kitoh, A., Laîné, A., Loutre, M.-F., Marti, O., Merkel, U., Ramstein, G., Valdes, P., Weber, S. L., Yu, Y., and Zhao, Y.: Results of PMIP2 coupled simulations of the Mid-Holocene and Last Glacial Maximum Part 1: experiments and large-scale features, Clim. Past, 3, 261277, doi:10.5194/cp-3-261-2007, 2007a.

Braconnot, P., Otto-Bliesner, B., Harrison, S., Joussaume, S., Peterchmitt, J.-Y., Abe-Ouchi, A., Crucifix, M., Driesschaert, E., Fichefet, Th., Hewitt, C. D., Kageyama, M., Kitoh, A., Loutre, M.-F., Marti, O., Merkel, U., Ramstein, G., Valdes, P., Weber, L., Yu, Y., and Zhao, Y.: Results of PMIP2 coupled simulations of the Mid-Holocene and Last Glacial Maximum Part 2: feedbacks with emphasis on the location of the ITCZ and mid- and high latitudes heat budget, Clim. Past, 3, 279-296, doi:10.5194/cp-3-279-2007, 2007b.

Bretagnon, P.: Théorie du mouvement de l'ensemble des planètes. Solution VSOP82, Astron. Astrophys., 30, 141-154, 1982.

Brohan, P, Kennedy, J. J., Harris, I., Tett, S. F. B., and Jones, P. D.: Uncertainty estimates in regional and global observed temperature changes: a new dataset from 1850, J. Geophys. Res., 11(D12), D12106, doi:10.1029/2005JD006548, 2006.

Brovkin, V., Bendsten, J., Claussen, M., Ganopolski, A., Kubatzki, C., Petoukhov, V., and Andreev, A.: Carbon cycle, vegetation and climate dynamics in the Holocene: Experiment with the CLIMBER-2 model, Global Biogeochem. Cy., 16(4), 1139, doi:10.1029/2001GB001662, 2002.

Brovkin, V., Claussen, V., Driesschaert, E., Fichefet, T., Kicklighter, D., Loutre, M. F., Matthews, H. D., Ramankutty, N., Schaeffer, M., and Sokolov, A.: Biogeophysical effects of historical land cover changes simulated by six Earth system models of intermediate complexity, Clim. Dynam., 26(6), 587-600, doi:10.1007/s00382-005-0092-6, 2006.

Charlson, R., Langmer, J., Rodhe, H., Levoy, C., and Warren, S.: Perturbation of the Northern hemisphere radiative balance by backscattering from anthropogenic sulfate aerosols, Tellus, 43(AB), 152-163, 1991. 
Comiso, J. C. and Nishio, F.: Trends in the Sea Ice Cover Using Enhanced and Compatible AMSR-E, SSM/I, and SMMR Data, nsidc.org/data/smmr_ssmi_ancillary/area_extent.html, last access: 19 August 2009, J. Geophys. Res., 113, C02S07, doi:10.1029/2007JC004257, 2008.

Crowley, T.: Causes of climate change over the past 1000 years, Science, 289, 270-277, 2000.

Driesschaert, E., Fichefet, T., Goosse, H., Huybrechts, P., Janssens, I., Mouchet, A., Munhoven, G., Brovkin, V., and Weber, S. L.: Modeling the influence of Greenland ice sheet melting on the meridional overturning circulation during the next millennia, Geophys. Res. Lett., 34, L10707, doi:10.1029/2007GL029516, 2007.

Dutay, J.-C., Jean-Baptiste, P., Campin, J.-M., Ishida, A., MaierReimer, E., Matear, R. J., Mouchet, A., Totterdell, I. J., Yamanaka, Y., Rodgers, K., Madec, G., and Orr, J. C.: Evaluation of OCMIP-2 ocean models' deep circulation with mantle helium3. J. Mar. Syst., 48, 15-36, doi:10.1016/j.jmarsys.2003.05.010, 2004.

Enting, I. G., Wigley, T. M. L., and Heimann, M.: Future Emissions and Concentrations of Carbon Dioxide: Key Ocean/Atmosphere/Land Analyses, CSIRO Aust. Div. Atmos. Res. Tech. Pap., 31, 1-118, 1994.

Flückiger, J., Monnin, E., Stauffer, B., Schwander, J., Stocker, T. F., Chappellaz, J., Raynaud, D., and Barnola, J.-M.: Highresolution Holocene $\mathrm{N}_{2} \mathrm{O}$ ice core record and its relationship with $\mathrm{CH}_{4}$ and $\mathrm{CO}_{2}$, Global Biogeochem. Cy., 16(1), 1010, doi:10.1029/2001GB001417, 2002.

Forster, P., Ramaswamy, V., Artaxo, P., Berntsen, T., Betts, R., Fahey, D. W., Haywood, J., Lean, J., Lowe, D. C., Myhre, G., Nganga, J., Prinn, R., Raga, G., Schulz, M., and Van Dorland, R.: Changes in Atmospheric Constituents and in Radiative Forcing, in: Climate Change 2007: The Physical Science Basis. Contribution of Working Group I to the Fourth Assessment Report of the Intergovernmental Panel on Climate Change, edited by: Solomon, S., Qin, D., Manning, M., Chen, Z., Marquis, M., Averyt, K. B., Tignor, M., and Miller, H. L., Cambridge University Press, Cambridge, UK and New York, NY, USA, 2007.

Frank, D. C., Esper, J., Raible, C. C., Büntgen, U., Trouet, V., Stocker, B., and Joos, F.: Ensemble reconstruction constraints on the global carbon cycle sensitivity to climate, Nature, 463, 527-532, doi:10.1038/nature08769, 2010.

Friedlingstein, P., Dufresne, J.-L., Cox, P. M., and Rayner, P.: How positive is the feedback between climate change and the carbon cycle?, Tellus B, 55, 692-700, 2003.

Gleckler, P. J., Taylor, K. E., and Doutriaux, C.: Performance metrics for climate models, J. Geophys. Res., 113(D6), D06104, doi:10.1029/2007JD008972, 2008.

GLOBALVIEW-CO2: Cooperative Atmospheric Data Integration Project - Carbon Dioxide, CD-ROM, NOAA GMD, Boulder, Colorado, also available on Internet via anonymous FTP to ftp.cmdl.noaa.gov, Path: ccg/co2/GLOBALVIEW (last access: 15 September 2009), 2006.

Goelzer, H., Huybrechts, P., Loutre, M. F., Goosse, H., Fichefet, T., and Mouchet, A.: Impact of Greenland and Antarctic ice sheet interactions on climate sensitivity, Clim. Dynam., doi:10.1007/s00382-010-0885-0, in press, 2010.

Goosse, H. and Fichefet, T.: Importance of ice-ocean interactions for the global ocean circulation : A model study, J. Geophys.
Res., 104, 23337-23355, 1999.

Goosse, H., Crowley, T., Zorita, E., Ammann, C., Renssen, H., and Driesschaert, E.: Modelling the climate of the last millennium: What causes the differences between simulations?, Geophys. Res. Lett., 32, L06710, doi:10.1029/2005GL22368, 2005.

Goosse, H., Driesschaert, E., Fichefet, T., and Loutre, M.-F.: Information on the early Holocene climate constrains the summer sea ice projections for the 21st century, Clim. Past, 3, 683-692, doi:10.5194/cp-3-683-2007, 2007.

Goosse, H., Brovkin, V., Fichefet, T., Haarsma, R., Huybrechts, P., Jongma, J., Mouchet, A., Selten, F., Barriat, P.-Y., Campin, J.M., Deleersnijder, E., Driesschaert, E., Goelzer, H., Janssens, I., Loutre, M.-F., Morales Maqueda, M. A., Opsteegh, T., Mathieu, P.-P., Munhoven, G., Pettersson, E. J., Renssen, H., Roche, D. M., Schaeffer, M., Tartinville, B., Timmermann, A., and Weber, S. L.: Description of the Earth system model of intermediate complexity LOVECLIM version 1.2, Geosci. Model Dev., 3, 603-633, doi:10.5194/gmd-3-603-2010, 2010.

Gregory, J. M., Stouffer, R. J., Raper, S. C. B., Stott, P. A., and Rayner, N. A.: An observationally based estimate of the climate sensitivity, J. Climate, 15, 3117-3121, 2002.

Gregory, J. M., Dixon, K. W., Stouffer, R. J., Weaver, A. J., Driesschaert, E., Eby, M., Fichefet, T., Hasumi, H., Hu, A., Jungclaus, J. H., Kamenkovich, I. V., Levermann, A., Montoya, M., Murakami, S., Nawrath, S., Oka, A., Sokolov, A. P., and Thorpe, R. B.: A model intercomparison of changes in the Atlantic thermohaline circulation in response to increasing atmospheric $\mathrm{CO}_{2}$ concentration, Geophys. Res. Lett., 32, L12703, doi:10.1029/2005GL023209, 2005.

Houghton, J. T., Jenkins, G. J., and Ephraums, J. J.: Climate Change: The IPCC Scientific Assessment, Cambridge University Press, Cambridge, 365 pp., 1990.

Houghton, J. T., Ding, Y., Griggs, D. J., Noguer, M., van der Linden, P. J., Dai, X., Maskell, K., and Johnson, C. A.: Climate Change 2001:The Scientific Basis. Contribution of Working Group I to the Third Assessment Report of the Intergovernmental Panel on Climate Change, Cambridge University Press, 881p., 2001.

Houghton, R. A.: Revised estimates of the annual net flux of carbon to the atmosphere from changes in land use and land management 1850-2000, Tellus B, 55(2), 378-390, 2003.

Huybrechts, P.: A 3-D model for the Antarctic ice sheet: a sensitivity study on the glacial-interglacial contrast, Clim. Dynam., 5, 79-92, 1990.

Huybrechts, P.: Basal temperature conditions of the Greenland ice sheet during the glacial cycles, Ann. Glaciol., 23, 226-236, 1996.

Huybrechts, P. and de Wolde, J.: The dynamic response of the Greenland and Antarctic ice sheets to multiple-century climatic warming, J. Climate, 12, 2169-2188, 1999.

IPCC: Climate Change 2007: The Physical Science Basis, in: Contribution of Working Group I to the Fourth Assessment Report of the Intergovernmental Panel on Climate Change, edited by: Solomon, S., Qin, D., Manning, M., Chen, Z., Marquis, M., Averyt, K. B., Tignor, M., and Miller, H. L., Cambridge University Press, Cambridge, UK and New York, NY, USA, 996 pp., 2007.

Knutti, R., Allen, M. R., Friedlingstein, P., Gregory, J. M., Hegerl, G. C., Meehl, G. G. A., Meinshausen, M., Murphy, J. M., Plattner, G.-K., Raper, S. C. B., Stocker, T. F. Stott, P. A., Teng, H., and Wigley, T. M. L.: A Review of Uncertainties in Global Temperature Projections over the Twenty-First Century, J. Climate, 
21, 2651-2663, doi:10.1175/2007JCLI2119.1, 2008.

Levitus, S., Antonov, J. I., Boyer, T. P. , Locarnini, R. A., Garcia, H. E., and Mishonov, A. V.: Global ocean heat content 1955-2008 in light of recently revealed instrumentation problems, Geophys. Res. Lett., 36, L07608, doi:10.1029/2008GL037155, 2009.

Marland, G., Boden, T., and Andres, R.: Global, Regional, and National Annual $\mathrm{CO}_{2}$ Emissions from Fossil-Fuel Burning, Cement Production, and Gas Flaring: 1751-2000, in : Trends: A compendium of data on global change, published by Carbon Dioxide Information Analysis Center, Oak Ridge, Tennessee, 2003.

Meehl, G. A., Stocker, T. F., Collins, W. D., Friedlingstein, P., Gaye, A. T., Gregory, J. M., Kitoh, A., Knutti, R., Murphy, J. M., Noda, A., Raper, S. C. B., Watterson, I. G., Weaver, A. J., and Zhao, Z.-C.: Global Climate Projections, in: Climate Change 2007: The Physical Science Basis. Contribution of Working Group I to the Fourth Assessment Report of the Intergovernmental Panel on Climate Change, edited by: Solomon, S., Qin, D., Manning, M., Chen, Z., Marquis, M., Averyt, K. B., Tignor, M., and Miller, H. L., Cambridge University Press, Cambridge, UK and New York, NY, USA, 2007.

Menviel, L., Timmermann, A., Mouchet, A., and Timm, O.: Meridional reorganizations of marine and terrestrial productivity during Heinrich events, Paleoceanography, 23(1), PA1203, doi:10.1029/2007PA001445, 2008a.

Menviel, L., Timmermann, A., Mouchet, A., and Timm, O.: Climate and marine carbon cycle response to changes in the strength of the Southern Hemispheric westerlies, Paleoceanography, 23(4), PA4201, doi:10.1029/2008PA001604, 2008b.

Meure, C. M., Etheridge, D., Trudinger, C., Steele, P., Langenfelds, R., van Ommen, T., Smith, A., and Elkins, J.: Law Dome $\mathrm{CO}_{2}$, $\mathrm{CH}_{4}$ and $\mathrm{N}_{2} \mathrm{O}$ ice core records extended to 2000 years BP, Geophys. Res. Lett., 3(14), L14810, doi:10.1029/2006GL026152, 2006.

Monnin, E., Steig, E. J., Siegenthaler, U., Kawamura, K., Schwander, J., Stauffer, B., Stocker, T. F., Morse, D. L., Barnola, J. M., Bellier, B., Raynaud, D., and Fischer, H.: Evidence for substantial accumulation rate variability in Antarctica during the Holocene, through synchronization of $\mathrm{CO}_{2}$ in the Taylor Dome, Dome C and DML ice cores, Earth Planet. Sc. Lett., 224(1-2), 45-54, doi:10.1016/j.eps1.2004.05.007, 2004.

Mouchet, A.: A 3D model of ocean biogeochemical cycles and climate sensitivity studies. $\mathrm{PhD}$ thesis, Université de Liège, Liège, Belgium, in preparation, 2011.

Mouchet, A. and François, L. M.: Sensitivity of a global oceanic carbon cycle model to the circulation and to the fate of organic matter: preliminary results, Phys. Chem. Earth, 21, 511-516, 1996.

Murphy, J. M., Sexton, D. M. H., Barnett, D. N., Jones, G. S., Webb, M. J., Collins, M., and Stainforth, A. A.: Quantification of modelling uncertainties in a large ensemble of climate change simulations, Nature, 430, 768-772, 2004.

Muscheler, R., Joos, F., Beer, J., Muller, S. A., Vonmoos, M., and Snowball, I.: Solar activity during the last $1000 \mathrm{yr}$ inferred from radionuclide records, Quaternary Sci. Rev., 26(1-2), 82-97, 2007.

Nakicenovic, N. and Swart, R.: Special report on emissions scenarios, A special report of Working Group III of the Intergovernmental Panel on Climate Change, Cambridge University Press, Cambridge, UK and New York, NY, USA, 599 pp., 2000.
NOAA ESRL: www.esrl.noaa.gov/gmd/ccgg/trends/ last access: 13 July, 2009.

Opsteegh, J. D., Haarsma, R. J., Selten, F. M., and Kattenberg, A.: ECBILT: A dynamic alternative to mixed boundary conditions in ocean models, Tellus A, 50, 348-367, 1998.

Pongratz, J., Reick, C., Raddatz, T., and Claussen, M.: A reconstruction of global agricultural areas and land cover for the last millennium, Global Biogeochem. Cy., 22, GB3018, doi:10.1029/2007GB003153, 2008.

Prather, M., Ehhalt, D., Dentener, F., Derwent, R., Dlugokencky, E., Holland, E., Isaksen, I., Katima, J., Kirchhoff, V., Matson, P., Midgley, P., and Wang, M.: Atmospheric chemistry and greenhouse gases. In: Climate Change 2001: The Scientific Basis. Contribution of Working Group I to the Third Assessment Report of the Intergovernmental Panel on Climate Change, edited by: Houghton, J. T., Ding, Y., Griggs, D. J., Noguer, M., van der Linden, P. J., Dai, X., Maskell, K., and Johnson, C. A., Cambridge University Press, Cambridge, UK and New York, NY, USA, 881 pp., 2001.

Rahmstorf, S., Crucifix, M., Ganopolski, A., Goosse, H., Kamenkovich, I., Knutti, R., Lohmann, G., Marsh, B., Mysak, L., Wang, Z., and Weaver, A.: Thermohaline circulation hysteresis: a model intercomparison, Geophys. Res. Lett., 32, L23605, doi:10.1029/2005GL023655, 2005.

Ramankutty, N. and Foley, J. A.: Estimating historical changes in global land cover: Croplands from 1700 to 1992, Global Biogeochem. Cy., 13(4), 997-1027, 1999.

Randall, D. A., Wood, R. A., Bony, S., Colman, R., Fichefet, T., Fyfe, J., Kattsov, V., Pitman, A., Shukla, J., Srinivasan, J., Stouffer, R. J., Sumi, A., and Taylor, K. E.: Climate Models and Their Evaluation, in: Climate Change 2007: The Physical Science Basis. Contribution of Working Group I to the Fourth Assessment Report of the Intergovernmental Panel on Climate Change, edited by: Solomon, S., Qin, D., Manning, M., Chen, Z., Marquis, M., Averyt, K. B., Tignor, M., and Miller, H. L., Cambridge University Press, Cambridge, UK and New York, NY, USA, 2007.

Siegenthaler, U., Monnin, E., Kawamura, K., Spahni, R., Schwander, J., Stauffer, B., Stocker, T. F., Barnola, J.-M., and Fischer, H.: Supporting evidence from the EPICA Dronning Maud Land ice core for atmospheric $\mathrm{CO}_{2}$ changes during the past millennium, Tellus B, 57(7), 51-57, doi:10.1111/j.16000889.2005.00131.x, 2005.

Stainforth, D. A., Aina, T., Christensen, C., Collins, M., Faull, N., Frame, D. J., Kettleborough, J. A., Knight, S., Martin, A., Murphy, J. M., Piani, C., Sexton, D., Smith, L. A., Spicer, R. A., Thorpe, A. J., and Allen, M. R.: Uncertainty in predictions of the climate response to rising levels of greenhouse gases, Nature, 433, 403-406, doi:10.1038/nature03301, 2005.

Stainforth, D. A., Allen, M. R., Tredger, E. R., and Smith, L. A.: Confidence, uncertainty and decision-support relevance in climate predictions, Philos. T. Roy. Soc. A, 365, 2145-2161, 2007.

Weber, S. L., Drijfhout, S. S., Abe-Ouchi, A., Crucifix, M., Eby, M., Ganopolski, A., Murakami, S., Otto-Bliesner, B., and Peltier, W. R.: The modern and glacial overturning circulation in the Atlantic ocean in PMIP coupled model simulations, Clim. Past, 3, 51-64, doi:10.5194/cp-3-51-2007, 2007. 